\title{
Treatment of murine Th1- and Th2-mediated inflammatory bowel disease with NF-kB decoy oligonucleotides
}

\author{
Stefan Fichtner-Feigl, Ivan J. Fuss, Jan C. Preiss, Warren Strober, and Atsushi Kitani \\ Mucosal Immunity Section, Laboratory of Host Defenses, National Institute of Allergy and Infectious Diseases, NIH, Bethesda, Maryland, USA.
}

\begin{abstract}
The Th1 and Th2 $\mathrm{T}$ cell responses that underlie inflammatory bowel diseases (IBDs) are likely to depend on NF- $\kappa B$ transcriptional activity. We explored this possibility in studies in which we determined the capacity of NF- $\kappa$ B decoy oligodeoxynucleotides (decoy ODNs) to treat various murine models of IBD. In initial studies, we showed that i.r. (intrarectal) or i.p. administration of decoy ODNs encapsulated in a viral envelope prevented and treated a model of acute trinitrobenzene sulfonic acid-induced (TNBS-induced) colitis, as assessed by clinical course and effect on Th1 cytokine production. In further studies, we showed that NF- $\kappa$ B decoy ODNs were also an effective treatment of a model of chronic TNBS-colitis, inhibiting both the production of IL-23/IL-17 and the development of fibrosis that characterizes this model. Treatment of TNBS-induced inflammation by i.r. administration of NF- $\kappa B$ decoy ODNs did not inhibit NF- $\kappa B$ in extraintestinal organs and resulted in CD4 ${ }^{+}$ $T$ cell apoptosis, suggesting that such treatment is highly focused and durable. Finally, we showed that NF- $\mathrm{B}$ decoy ODNs also prevented and treated oxazolone-colitis and thus affect a Th2-mediated inflammatory process. In each case, decoy administration led to inflammation-clearing effects, suggesting a therapeutic potency applicable to human IBD.
\end{abstract}

\section{Introduction}

Results of recent studies of the idiopathic inflammatory bowel diseases (IBDs; Crohn disease and ulcerative colitis) strongly suggest that these diseases are due to inappropriate and/or excessive responses to antigens present in the normal bacterial microflora (1-6). Crohn disease is characterized by a transmural, granulomatous inflammation occurring anywhere in the alimentary canal but is usually centered in the terminal ileum and ascending colon; ulcerative colitis, in contrast, is marked by a superficial inflammation causing epithelial cell destruction (ulceration) that is centered in the rectum and colon (1, 2). Despite having a common basis in overresponsiveness to mucosal antigens, the 2 diseases have considerably different pathophysiologies. Crohn disease is associated with a Th1 T cell-mediated response induced by IL-12 and possibly IL-23, whereas ulcerative colitis is associated with an atypical Th2-mediated response characterized by NKT cell secretion of IL-13 (6-10). In recent years, a great number of murine models of mucosal inflammation mimicking these diseases have been described, and their study has led to a profound increase in our understanding of their immunologic bases. One such model, hapten-induced colitis in mice caused by intrarectal (i.r.) instillation of trinitrobenzene sulfonic acid (TNBS-colitis) is a Th1 T cell-mediated colitis that captures many of the features of Crohn disease (11-14). On the other hand, a second hapten-induced colitis in mice (oxazolone-colitis), caused by i.r. instillation of oxazolone, reproduces many of the features of ulcerative colitis $(5,15)$.

Both in human IBD and in murine models of IBD, the inflammation is likely to depend, at least in part, on the activation and

Nonstandard abbreviations used: HVJ-E, viral envelope derived from the hemagglutinating virus of Japan; IBD, inflammatory bowel disease; i.r., intrarectal(ly); IRF4, IFN regulatory factor 4; LPMC, lamina propria mononuclear cell; ODN, oligodeoxynucleotide; TNBS, trinitrobenzene sulfonic acid.

Conflict of interest: The authors have declared that no conflict of interest exists.

Citation for this article: J. Clin. Invest. 115:3057-3071 (2005).

doi:10.1172/JCI24792. nuclear translocation of NF- $\mathrm{BB}$ family members (16-19). This would certainly be the case in Th1-mediated inflammations dependent on IL-12 and/or IL-23, since the synthesis of these cytokines is regulated by NF- $\kappa \mathrm{B}$ transcription factors (20-23). In addition, it would also be true of Th2-mediated inflammations if these inflammations depend on IL-4 or IL-13, since the synthesis of these cytokines is also dependent on NF- $\kappa \mathrm{B}$ transcription factors, albeit more indirectly than IL-12/IL-23 (24-26). This suggests that one method of treating the inflammation of IBD is to administer agents that inhibit NF-кB activity, and indeed, in previous studies of hapten-induced murine models of IBD, inflammation has been successfully prevented with the administration of antisense oligodeoxynucleotides (ODNs) specific for the p65 component of NF- $\mathrm{KB}(16,27)$. If this approach is to be applied to the treatment of IBD in humans, however, it must be shown that such agents can very effectively reverse established disease when cytokines not directly dependent on NF- $\mathrm{KB}$ may be operative. In addition, it must be shown that such agents can have major therapeutic effects in Th2 as well as Th1 inflammations. Finally, methods of delivering anti-NF- $\mathrm{BB}$ agents to intracellular sites within the inflamed tissue must be devised to achieve an effective level of therapy with concentrations of inhibitors that do not have widespread toxic effects.

The major family of NF- $\kappa \mathrm{B}$ transcription factors consists of 5 members, c-Rel, p65, RelB, p50, and p52, all of which contain domains that bind to a similar binding site in the promoters of genes encoding key inflammatory proteins (such as IL-12 and IL-23) (28). This creates the possibility of blocking most forms of

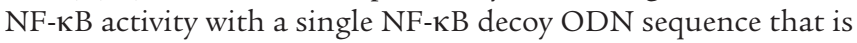
identical to the consensus sequence of the NF- $\kappa \mathrm{B}$ binding site. In this study, we utilized a decoy with such a consensus binding site sequence in association with a novel way of delivering the NF- $\mathrm{KB}$ decoy ODNs to the inside of cells. The latter involves the delivery of decoy ODNs in a viral envelope derived from the hemaggluti- 


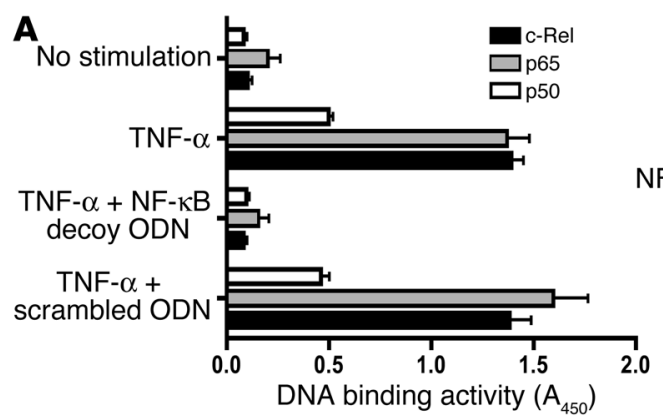

B

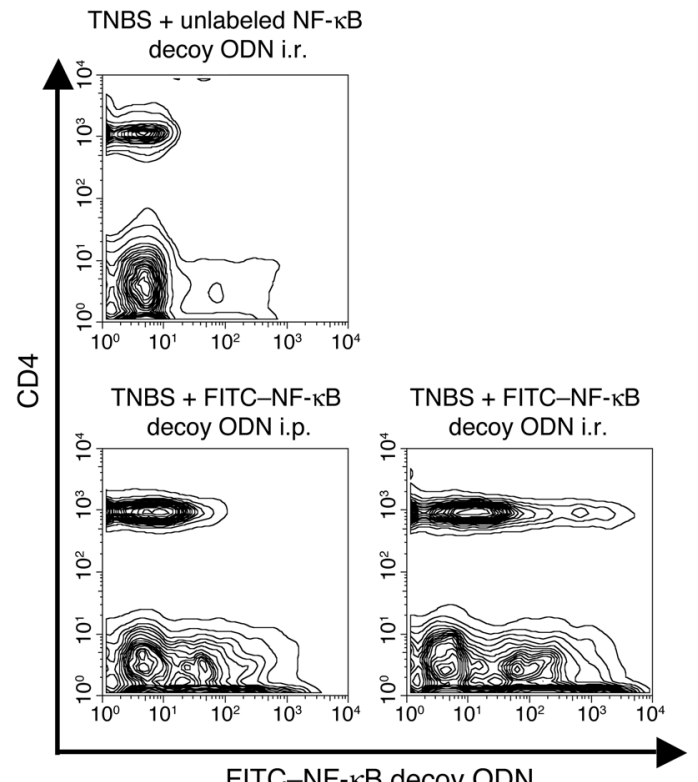

FITC-NF-kB decoy ODN

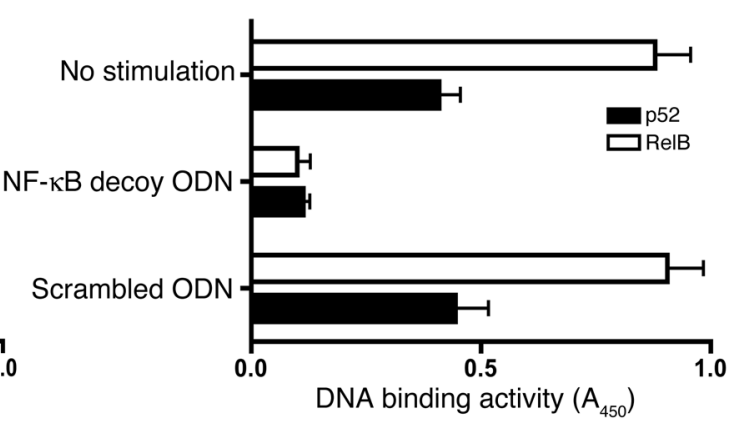

Figure 1

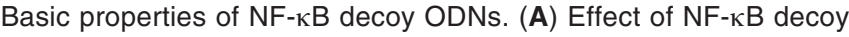
ODNs on NF-KB DNA-binding activity. HeLa cells activated by TNF- $\alpha$ $(20 \mathrm{ng} / \mathrm{ml})$ or Raji cells (constitutively activated) were transfected with NF-KB decoy ODNs or scrambled ODNs encapsulated in a HVJ-E; 30 minutes after stimulation, the binding activity of p65, c-Rel, and p50 was determined in nuclear extracts of HeLa cells, whereas binding activity of Rel B and p52 was directly determined in nuclear extracts of Raji cells using the TransFactor assay. Data shown are mean values \pm SD obtained from 2 independent experiments. Results are presented as absorbance at $450 \mathrm{~nm}\left(\mathrm{~A}_{450}\right)$ wave length. (B) In vivo transfection of NF-KB decoy ODNs into CD4+ ${ }^{+}$cells and non-CD4+ $T$ cells in the colonic lamina propria. Mice were administered FITC-

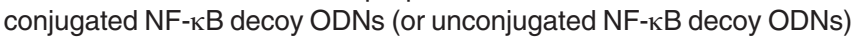
i.r. 4 hours after TNBS administration or i.p. 4, 24 , and 48 hours after TNBS administration; then, 5 days after TNBS-colitis induction, colonic lamina propria cells were isolated, stained with PE-anti-CD4, and analyzed by flow cytometry.

bound consensus binding sequence in the presence and absence of decoy ODNs using the TransFactor assay (see Methods). Nuclear extracts derived from HeLa cells subjected to TNF- $\alpha$ stimulation were the source of the activated NF- $\mathrm{KB}$ family members, p65, c-Rel, and p50, whereas unstimulated Raji cells (cells in which NF- $\mathrm{B}$ family members are constitutively activated) were the source of RelB and p52. The inhibitory effect of NF-кB decoy ODNs was compared with that of scrambled ODNs, a 22-bp double-stranded DNA sequence not containing any known binding sites for a transcription factor. As shown in Figure 1A, the ability of all measured NF- $\mathrm{KB}$ subunits to bind to the plate-bound consensus sequence was decreased to baseline levels by NF- $\kappa \mathrm{B}$ decoy ODNs, whereas scrambled ODNs showed no inhibitory effects. These findings indicate that NF- $\mathrm{KB}$ decoy ODNs are a potent inhibitor of all subunits of the NF-кB transcription factor family that might thus have similar inhibitory effects in vivo.

$N F-\kappa B$ decoy ODNs encapsulated in the HVJ-E are effectively transfected into both $\mathrm{CD}^{+} \mathrm{T}$ cells and non-T cells of the lamina propria. In further studies mapping the basic characteristics of NF-KB decoy ODN activity, we determined the types of cells undergoing in vivo transfection with decoy ODNs following both i.r. and i.p. administration of decoy ODNs. To this end, we administered FITC-conjugated NF- $\kappa B$ decoy ODNs encapsulated in HVJ-E after TNBS-colitis induction in $\mathrm{C} 57 \mathrm{BL} / 10$ mice via an i.r. or i.p. route. The decoy ODNs were administered once by the i.r. route, at 4 hours after TNBS induction, whereas it was administered 3 times by the i.p. 


\section{Figure 2}

Treatment of TNBS-colitis by administration of NF-KB decoy ODNs. (A-D) TNBS-colitis was induced by i.r. administration of TNBS in ethanol. Mice were treated with NF- $\kappa B$ decoy ODNs (or scrambled ODNs) via an i.r. route (at 4 hours) or via an i.p. route (at 4,24 , and 48 hours). Data shown are representative of 3 independent experiments. (A) Body weight as a percent of starting weight. Data shown are mean values $\pm S D$ and derived from at least 7 mice per group. (B) Animal survival during the first 5 days after TNBS administration. (C) H\&E staining of representative colon cross-sections on day 5 after TNBS administration. Magnification, $\times 5$. (D) Histological scores shown are mean values \pm SD from at least 7 mice per group. (E-H) TNBS-colitis was induced by i.r. administration of TNBS in ethanol. On day 5 , mice with at least $20 \%$ body weight loss and not in recovery phase were pooled and divided into treatment groups. Mice

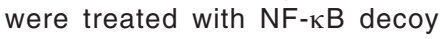
ODNs (or scrambled ODNs) via an i.r. route (day 5) or via an i.p. route (days $5-7$ ). Data shown are representative of 2 independent experiments. (E) Body weight as a percent of starting weight. Data shown are mean values \pm SD from at least 7 mice per group. (F) Animal survival in percent until day 9 after TNBS administration. (G) H\&E staining of representative colon cross-sections on day 9 after TNBS administration. Magnification, $\times 5$. (H) Histological scores are shown as mean values \pm SD from at least 7 mice per group. ${ }^{\star} P<0.05$.
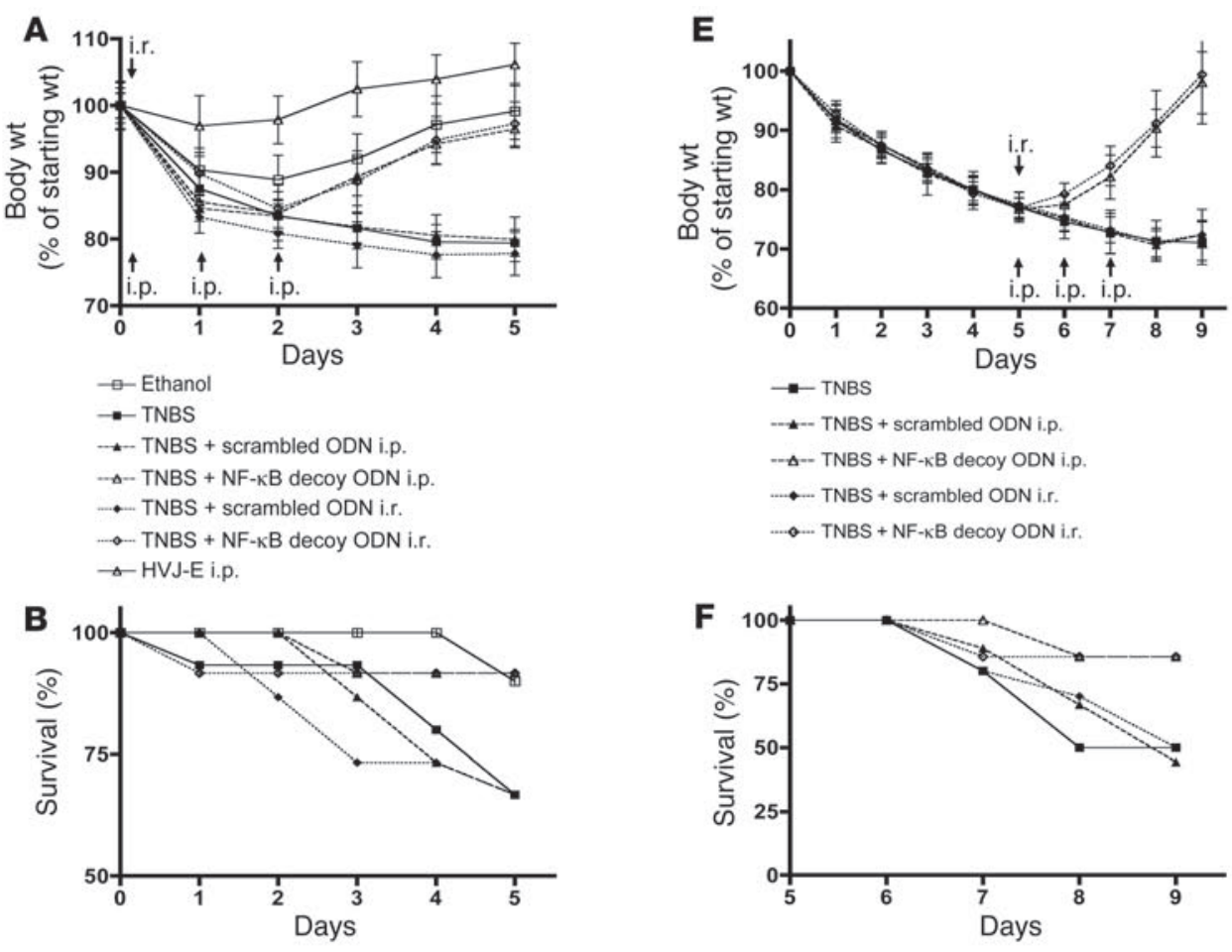

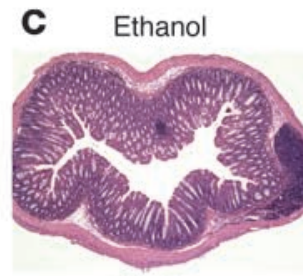

TNBS + scrambled ODN i.p.

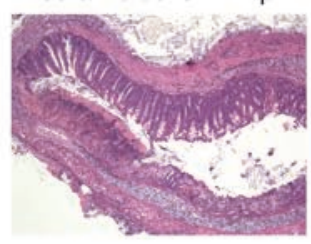

TNBS + scrambled ODN i.r.
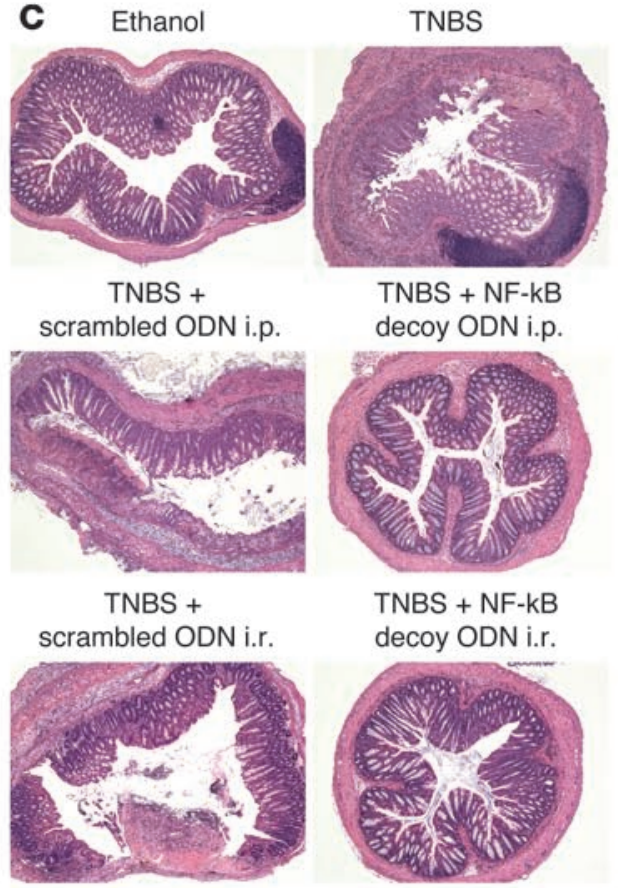

TNBS + NF-kB decoy ODN i.r.
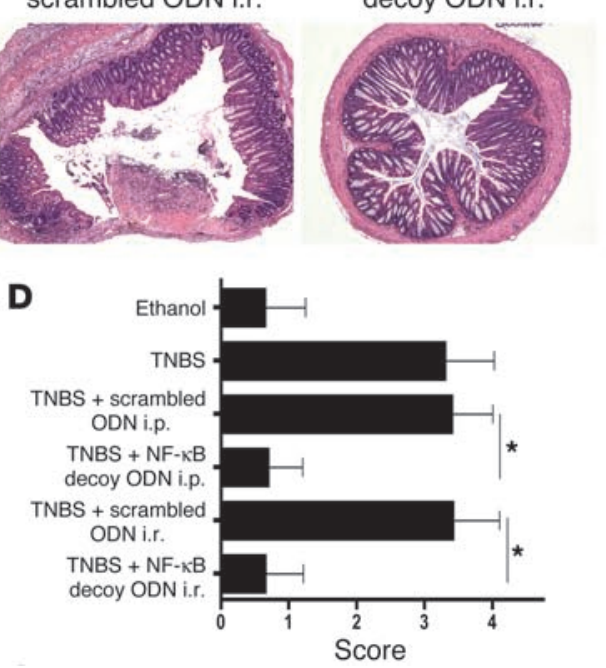

G TNBS

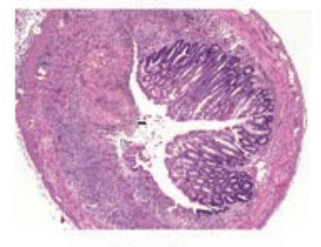

TNBS + scrambled ODN i.p.

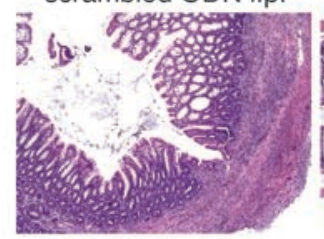

TNBS + scrambled ODN i.r.

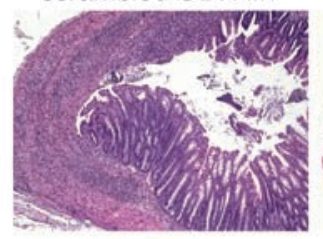

TNBS + NF-kB decoy ODN i.p.

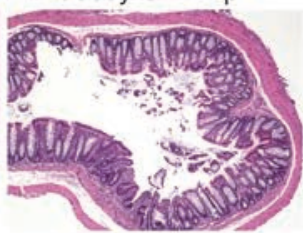

TNBS + NF-kB decoy ODN i.r.

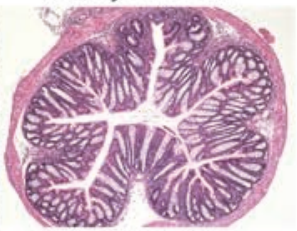

H

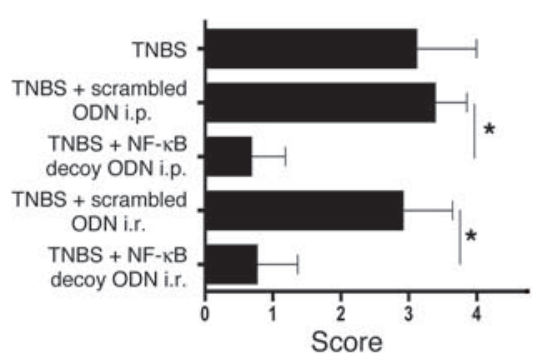


route, at 4, 24, and 48 hours after TNBS induction. Then, on day 5 after induction, colonic lamina propria mononuclear cells (LPMCs) were isolated and subjected to flow cytometry after staining with PE-labeled anti-CD4 Ab. As shown in Figure 1B, cells from mice administered unlabeled NF-кB decoy ODNs exhibited background FITC fluorescence (except for minimal autofluorescence most probably arising from epithelial cells). In contrast, cells from mice administered labeled decoy ODNs exhibited very considerable positive fluorescence in both $\mathrm{CD}^{+} \mathrm{T}$ cells and non-CD4 ${ }^{+}$cells (a cell population containing APCs, epithelial cells, and possibly $\mathrm{CD}^{+} \mathrm{T}$ cells). FITC-positive cells were seen in cell populations obtained from mice administered decoy ODNs by both the i.r. and i.p. routes, but was somewhat higher in the populations from mice given i.r. decoy ODNs. These studies establish that NF-KB decoy ODNs encapsulated in HVJ-E transfect both $\mathrm{CD}^{+} \mathrm{T}$ cells and non$\mathrm{CD}^{+}$cells following both i.r. and i.p. administration. It should be noted, however, that because the decoy ODNs could not be labeled with high intensity, the data shown offers a qualitative rather than quantitative estimate of cell transfection.

Administration of NF- $\kappa B$ decoy ODNs encapsulated in HVJ-E prevents nascent TNBS-colitis and reverses established TNBS-colitis. TNBS-colitis induced in $\mathrm{SJL} / \mathrm{J}$ or $\mathrm{C} 57 \mathrm{BL} / 10$ mice is a rapidly evolving transmural colitis that, like Crohn disease, is a Th1-mediated inflammation dependent on the production of IL-12 (and presumably IL-23). To determine whether NF-кB decoy ODNs could prevent the development of this colitis in C57BL/10 mice, we induced colitis in these mice by i.r. instillation of TNBS in ethanol (see Methods) and then, 4 hours later, instilled $75 \mu \mathrm{g}$ NF-кB decoy ODNs or scrambled ODNs (encapsulated in HVJ-E) (see Methods); alternatively, we administered these ODNs (again $75 \mu \mathrm{g}$ packaged in HVJ-E) by i.p. injection at 4 hours after TNBS administration and again on days 1 and 2 after TNBS administration. The mice were then monitored by weight loss (or gain), mortality, colon histology, and cytokine secretion by cells extracted from tissues and stimulated in vitro. As shown in the weight curves depicted in Figure 2A and the mortality graph depicted in Figure 2B, whereas mice administered TNBS/ethanol alone and treated with scrambled ODNs exhibited progressive weight loss and high

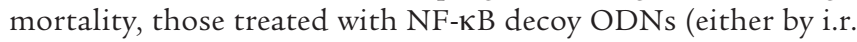
instillation or i.p. injections) had a course similar to that observed in control mice treated with ethanol alone or, indeed, HVJ-E alone (without ODNs). Similarly, the macroscopic appearance of the colons and, as shown in Figure 2, C and D, histological examination of the colons of the NF-KB decoy ODN-treated mice showed no evidence of inflammation, whereas the colons of the scrambled ODN-treated mice showed severe inflammation.

A more stringent test of the efficacy of NF- $\mathrm{KB}$ decoy ODNs as a treatment of TNBS-colitis is whether or not they can reverse already established colitis. To explore this question, we again induced TNBS-colitis in C57BL/10 mice and then monitored the mice for weight loss, ultimately only selecting those for treatment with NF-кB decoy ODNs (or scrambled ODNs) that had lost $20 \%$ of body weight by the fifth day after colitis induction. Then, on day 5 after colitis induction, we administered 1 dose of NF-кB decoy or scrambled ODNs $(75 \mu \mathrm{g})$ by the i.r. route or 3 doses of these ODNs by the i.p. route on consecutive days (in both cases encapsulated in HVJ-E) as in the prevention study described above. Care was taken to ensure that the various experimental groups to be compared had lost equivalent amounts of weight. As shown in Figure 2, E and $\mathrm{F}$, untreated mice and mice treated with scrambled ODNs continued to lose weight and exhibited a mortality rate at day 9 as high as $50 \%$. In contrast, mice that were treated with NF- $\mathrm{KB}$ decoy ODNs (by either the i.r. or i.p. route) exhibited a reversal in weight loss and a mortality rate of only $15 \%$ at day 9 . Furthermore, as shown in Figure 2, G and H, these weight loss and mortality data correlated with histological evaluation of colonic sections. In a similar experiment, mice were treated on day 4 and sacrificed on day 7 after TNBS administration, with comparable positive treatment effects by NF-кB decoy ODNs.

Finally, culture and stimulation of isolated colonic LPMCs from NF-кB decoy ODN-treated mice, obtained either from the mice administered NF- $\kappa$ B decoy ODNs at the time of TNBScolitis induction to prevent disease or 5 days after induction to treat established disease led to secretion of baseline levels of Th1 cytokines. In contrast, culture and stimulation of cells from untreated or scrambled ODN-treated mice led to secretion of high levels of these cytokines. Thus, as shown in Figure 3A, which depicts the cytokine response of cells isolated from mice with established TNBS-colitis, cells extracted from untreated mice or scrambled ODN-treated mice produced higher levels of IL-12 p70, TNF- $\alpha$, and IFN- $\gamma$ than did cells from mice treated with NF- $\kappa$ B decoy ODNs when appropriately stimulated in vitro (see Methods), whereas cells extracted from the lamina propria of NF- $\kappa$ B decoy ODN-treated mice exhibited levels of cytokine secretion similar to those observed in control ethanol-treated mice. However, as also shown in Figure 3A, secretion of IL-10, a cytokine with antiinflammatory properties, was greatly enhanced in mice treated with NF-KB decoy ODNs as compared with scrambled ODNtreated or untreated mice. Entirely similar cytokine responses were obtained with cells isolated from mice treated with NF-кB decoy ODNs at the time of TNBS-colitis induction (data not shown). Taken together, these data indicate that NF-кB decoy ODNs administered i.r. or i.p. are highly effective both in the prevention of nascent TNBS-colitis and in the treatment of established TNBScolitis. It should be noted that mice treated with "naked" NF-кB decoy ODNs not packaged in HVJ-E (at the time of TNBS-colitis induction), then monitored by all of the parameters mentioned above, exhibited no amelioration of colitis (data not shown). In addition, treatment of mice (at the time of TNBS-colitis induc-

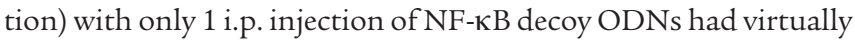
no effect on the development of TNBS-colitis.

The results of 2 subsequent studies correlated with and expanded on these results. First, we conducted studies to determine whether the administration of NF- $\mathrm{KB}$ decoy ODNs (encapsulated in HVJ-E) results in a persistent inhibition of NF- $\mathrm{-B}$ components (p65 and c-Rel) in the context of an existent inflammatory state. Accordingly, we obtained nuclear extracts of mononuclear cells isolated from the lamina propria of mice 4 days after i.r. administration of NF- $\mathrm{KB}$ decoy ODN or scrambled ODN treatment ( 9 days after induction of TNBS-colitis) and then estimated the DNA-binding activity of p65 and c-Rel in the extracts by the extent of binding of these components to plate-bound consensus $\mathrm{NF}-\kappa \mathrm{B}$ sequences in the TransFactor assay. As shown in Figure $3 \mathrm{~B}$, extracts of cells from NF- $\mathrm{KB}$ decoy ODN-treated mice exhibited greatly decreased p 65 and c-Rel binding to the consensus sequence, whereas the extracts of scrambled ODN-treated mice exhibited high levels of binding. These data indicate that suppression of binding of NF- $\mathrm{KB}$ components occurs during inflammation and, indeed, is present during the period when the inflammation is subsiding. The latter finding, together with the data 
A
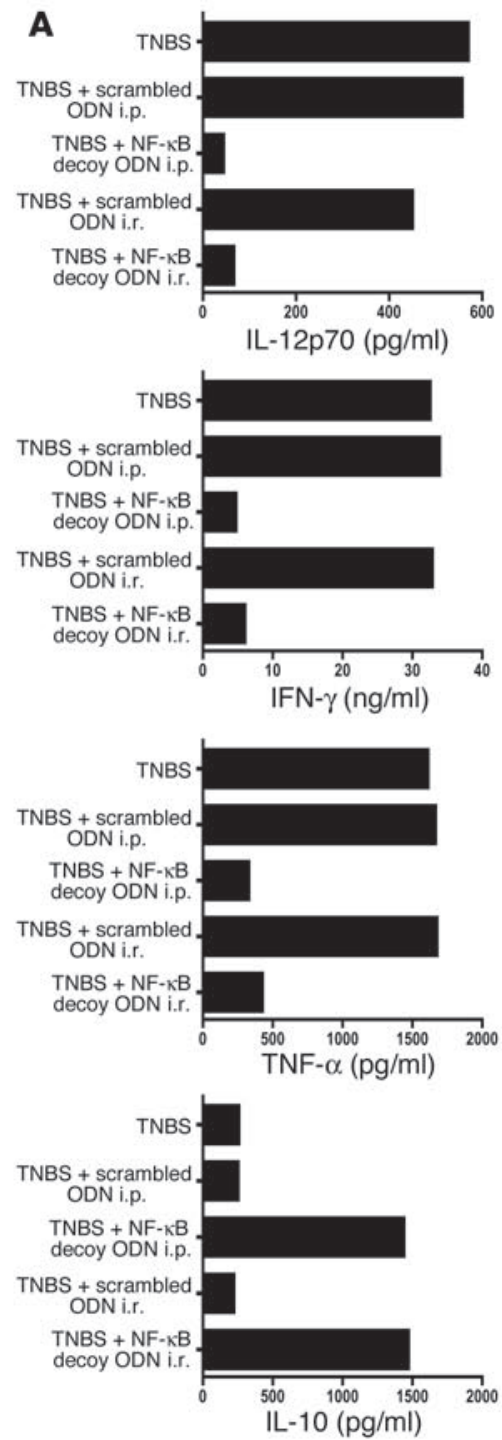

B
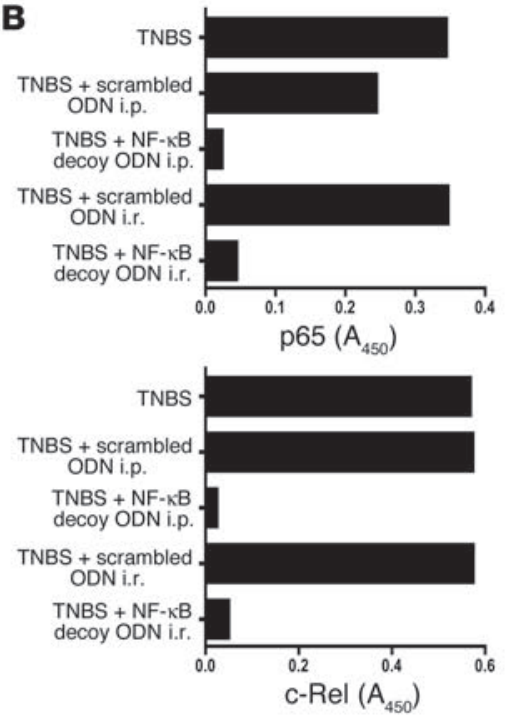

D

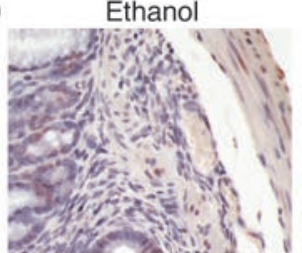

TNBS + scrambled ODN
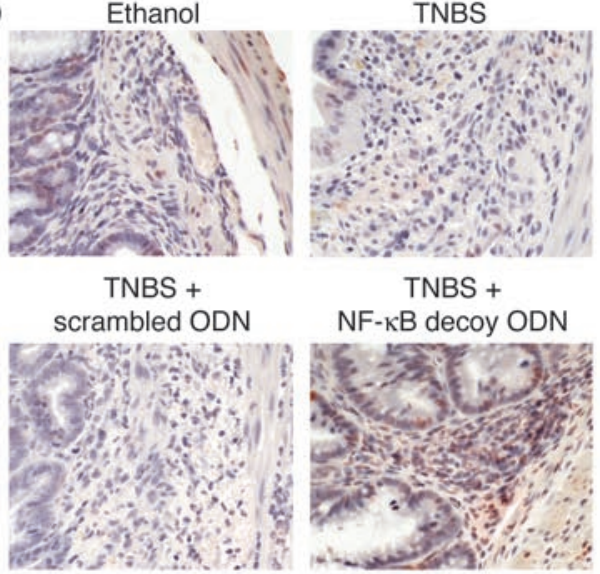

TNBS + NF-KB decoy ODN

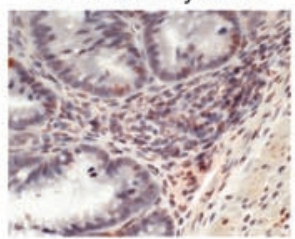

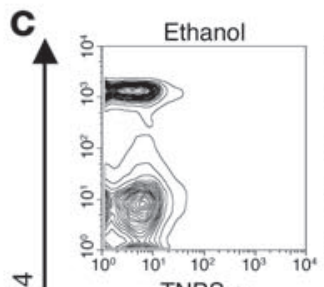

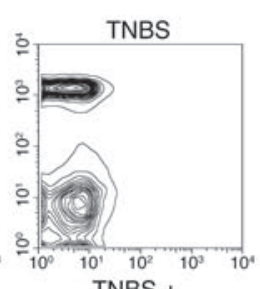

cramb

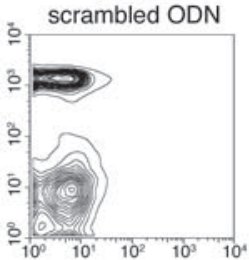

TNBS +

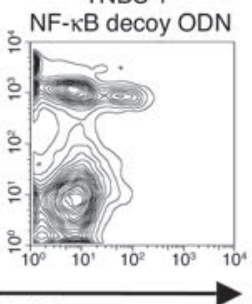

Annexin V

Figure 3

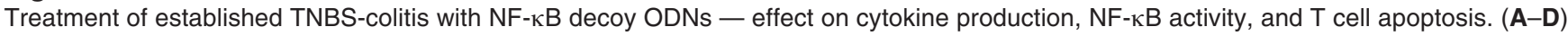
TNBS-colitis was induced by i.r. administration of TNBS in ethanol. On day 5 , mice with at least $20 \%$ weight loss and not in a recovery phase were pooled and divided into treatment groups. Mice were treated with NF-кB decoy ODNs (or scrambled ODNs) via an i.r. route (day 5) or via an i.p. route (days 5-7). Data shown are representative of 2 independent experiments. (A) Cytokine production of colonic lamina propria cells on day 9 after TNBS administration. Cells were extracted from the lamina propria and cultured for 48 hours in the presence of stimulants (see Methods). Cytokine concentration was determined in the supernatants by ELISA. (B) DNA-binding activity of p65 and c-Rel in nuclear extracts derived from colonic lamina propria cells on day 9 after TNBS administration and measured by TransFactor assay. (C) Apoptosis of CD4 ${ }^{+}$cells in colonic lamina propria 1 day after i.r. treatment of established TNBS-colitis. Mice were treated with NF-кB decoy ODNs (or scrambled ODNs) on day 5 , and colonic lamina propria cells were isolated on day 6 by flow cytometry. Apoptotic cells were determined by annexin $V$ staining. (D) TUNEL staining of representative colon cross-sections on day 7 after TNBS administration. Magnification, $\times 40$. Mice were treated with NF- $\mathrm{KB}$ decoy ODNs (or scrambled ODNs) on day 5, and colonic cross-sections were stained on day 7.

described above relating to the persistence of FITC-labeled NF- $\mathrm{KB}$ decoy ODNs, indicates that the inflammation-clearing effects of NF- $\mathrm{KB}$ decoy ODNs are surprisingly long lasting.

Second, we investigated whether or not NF-KB decoy ODN treatment is associated with apoptosis of effector cells in TNBS-colitis, as previously shown (13) in treatment of TNBS-induced colitis with anti-IL-12. To this end, on day 5 after induction of TNBS-colitis (or on day 5 after administration of ethanol alone), mice were i.r. treated with NF-KB decoy ODNs or scrambled ODNs; then, 24 hours later, colonic LPMCs were isolated and stained with annexin V (see Methods) for detection of apoptotic cells by flow cytometric analysis. As shown in Figure 3C, whereas in the untreated or scrambled ODN-treated TNBS-colitis mouse groups, or the ethanol-treated mouse group, less than $4 \%$ of the $\mathrm{CD} 4^{+}$cells were annexin $\mathrm{V}$ positive, in the i.r. NF- $\mathrm{kB}$ decoy ODN-treated TNBS-colitis mouse group, $23 \%$ of $C D 4^{+}$cells were annexin $V$ positive. To visualize this effect in situ, we performed TUNEL staining of colonic cross sections of mice with TNBS-colitis 2 days after treatment with NF-KB 


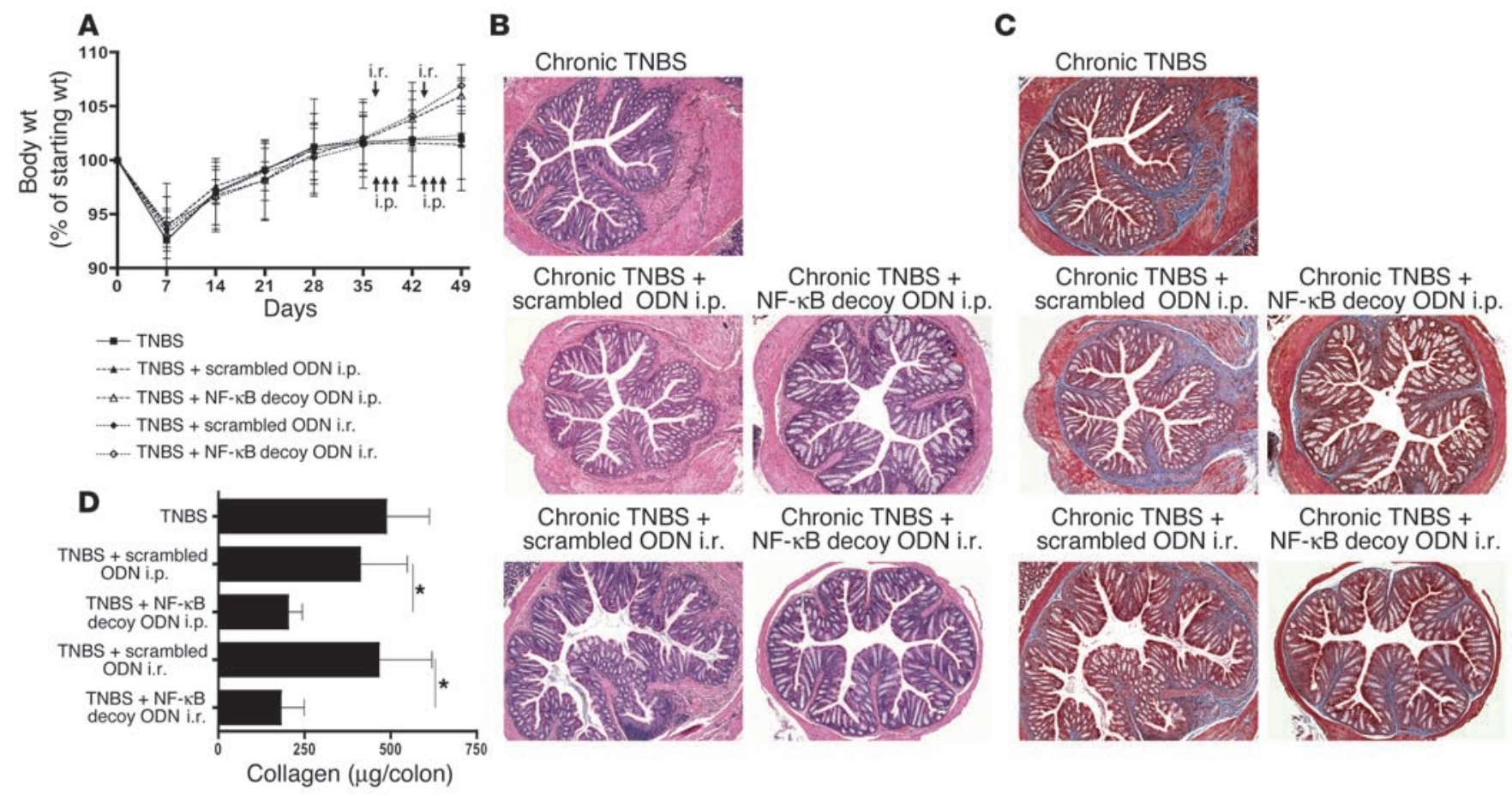

Figure 4

Treatment of chronic TNBS-colitis by NF-KB decoy ODNs. (A-D) Chronic TNBS-colitis was induced by 7 weekly i.r. administrations of TNBS in ethanol. Mice were treated with NF-KB decoy ODNs (or scrambled ODNs) via an i.r. route (day 37 and day 44) or via an i.p. route (days 37-39 and days 44-46). (A) Body weight as a percent of starting weight. Data are shown as mean values \pm SD and are representative of 2 independent experiments. (B) H\&E staining of representative colon cross-sections on day 49 after TNBS administration. Magnification, $\times 5$. (C) Masson trichrome staining of representative colon cross-sections on day 49 after TNBS administration. Magnification, $\times 5$. (D) Collagen content of the colon. Collagen content was determined on day 49 by a Sircol assay. Data shown are mean values \pm SD and are derived from at least 4 mice per group. ${ }^{*} P<0.05$.

decoy ODNs. As shown in Figure 3D, only colonic lamina propria of mice with TNBS-colitis and treated with NF- $\kappa$ B decoy ODNs showed increased numbers of TUNEL-positive inflammatory cells. These data show clearly that NF- $\mathrm{KB}$ decoy ODN administration causes apoptosis of $\mathrm{CD}^{+} \mathrm{T}$ cells in the inflamed gut, suggesting that this form of therapy might have durable effects.

In further studies to identify the cells subject to apoptosis following treatment with NF-кB decoy ODNs, we isolated colonic LPMCs and separated the latter into $\mathrm{CD}^{+}$and $\mathrm{CD} 11 \mathrm{~b}^{+}$subsets using $\mathrm{Ab}$-coated magnetic beads. After separation, we subjected a portion of the 2 cell

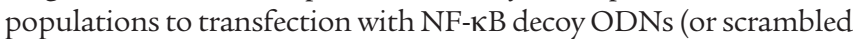
ODNs) and then cultured both transfected and untransfected cells with TNF- $\alpha$ for 24 hours. Finally, we determined the extent of apoptosis occurring in each cell population by flow cytometric analysis of annexin $V$ and propidium iodide staining. As shown in Supplemental Figure 1 (supplemental material available online with this article; doi:10.1172/JCI24792DS1), after in vitro culture and transfection of $\mathrm{CD}^{+}$and $\mathrm{CD} 11 \mathrm{~b}^{+}$cells, we found that both $\mathrm{CD}^{+}$and $\mathrm{CD} 11 \mathrm{~b}^{+}$ cells exhibited greatly enhanced apoptosis after transfection with NF- $\kappa B$ decoy ODNs when cultured with TNF- $\alpha$. The relatively high background apoptosis observed in control cultures was due to the fact that even after cell purification, the cell populations still contain substantial numbers of colonic epithelial cells and/or granulocytes that undergo cell death during the culture period. These data suggest that NF-кB decoy ODN treatment induces apoptosis in both T cell and APC populations and thus undermines the inflammationcausing immune response at 2 levels.
Administration of NF- $\mathrm{KB}$ decoy ODNs packaged in HVJ-E prevents the development of colonic fibrosis in chronic TNBS-colitis. In the studies described so far, the effects of NF-кB decoy ODNs were studied in an acute model of TNBS-colitis. Recently, a more chronic form of this type of experimental colitis has been reported in which the colitis is induced in BALB/c mice by weekly i.r. administration of increasing doses of TNBS (see Methods) (27). This form of TNBS-colitis in BALB/c mice differs from the more acute form in SJL/J or C57BL/10 mice by the fact that it has both a Th1 and Th 2 component. In addition, it leads to the development of fibrosis after the sixth week of TNBS treatment. This model therefore allowed us to again determine the effects of $\mathrm{NF}-\kappa \mathrm{B}$ decoy ODNs on an established colitis (in this case with a somewhat different pathophysiology) and at the same time to determine the effect of such treatment on the development of cytokine-mediated fibrosis.

In these studies we administered i.r. TNBS to mice each week for 7 weeks. On day 35 after initiation of TNBS administration, mice were assembled into weight-matched subgroups for various types of treatment. We treated one group of mice with i.r. NF-кB decoy ODNs encapsulated in HVJ-E on days 37 and 44 and a second group with i.p. NF-кB decoy ODNs daily on days 37-39 and days 44-46. A similar regimen was followed for mice treated with scrambled ODNs. It should be noted that the TNBS-colitis in these mice did not cause death after week 3 , suggesting that at this point the remaining mice had achieved a steady state of inflammation compatible with continued survival. 
A
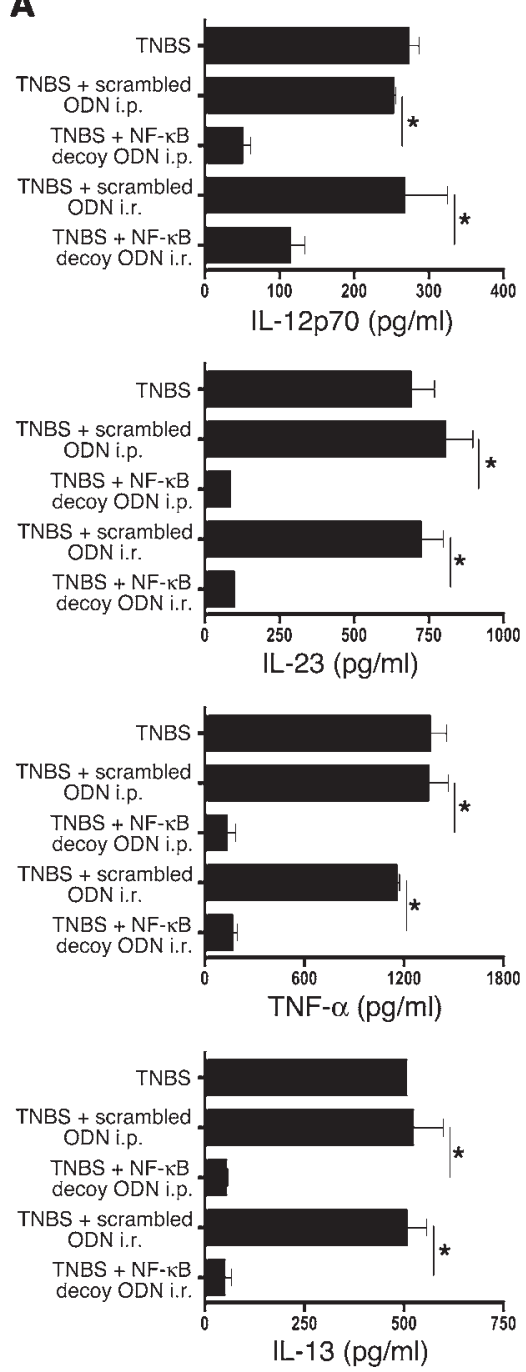

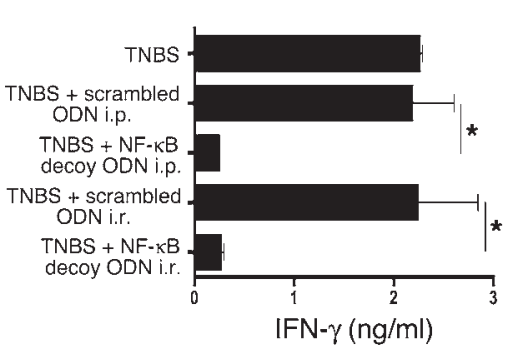

B
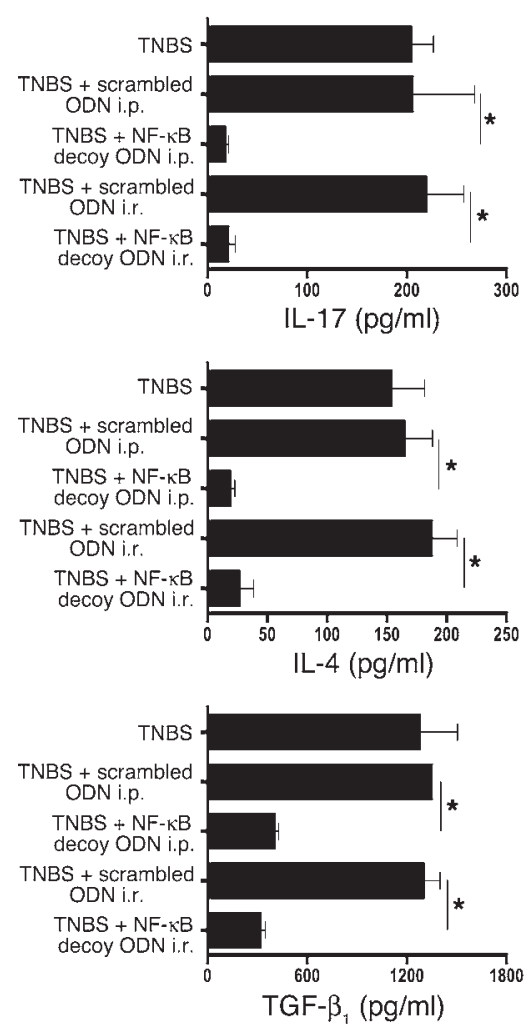

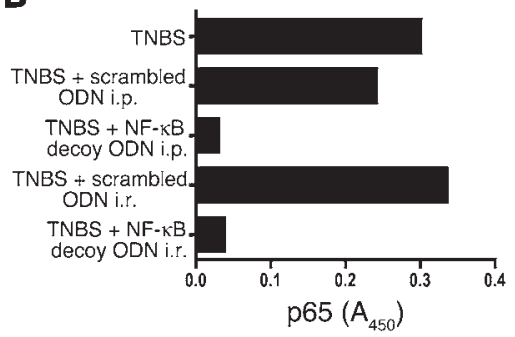

\section{Figure 5}

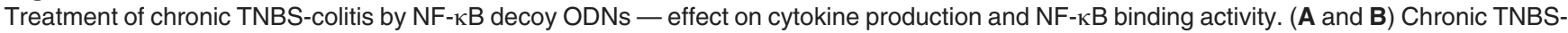
colitis was induced by 7 weekly i.r. administrations of TNBS in ethanol. Mice were treated with NF-kB decoy ODNs (or scrambled ODNs) via an i.r. route (day 37 and day 44) or via an i.p. route (days 37-39 and days 44-46). (A) Cytokine production of colonic lamina propria cells on day 49 after the initial TNBS administration. Cells were extracted from the lamina propria and cultured for 48 hours in the presence of stimulants (see Methods). Cytokine concentrations were determined in culture supernatants by ELISA. Data shown are mean values \pm SD and are representative of 2 independent experiments. (B) DNA-binding activity of p65 on day 49 after initial TNBS administration in nuclear extracts from colonic lamina propria cells, measured by TransFactor assay. ${ }^{*} P<0.01$.

As shown in Figure 4A, BALB/c mice administered TNBS as described above lost weight during the first 7 days following the initial dose of i.r. TNBS but thereafter gained weight and reached their starting weight by day 28 despite readministration of TNBS. In the following weeks, untreated mice and scrambled ODN-treated mice with chronic TNBS-colitis did not gain additional weight, whereas NF- $\kappa$ B decoy ODN-treated mice gained additional weight after their first treatment on day 37. As shown in Figure $4 \mathrm{~B}$, these weight changes correlated with the histological evaluation of colonic tissues of the various mouse groups. Untreated and scrambled ODN-treated mice with chronic TNBS-colitis exhibited inflammation of the colonic lamina propria as well as marked thickening of the colon wall, whereas NF- $\mathrm{BB}$ decoy ODN-treated mice showed comparatively little inflammation of the colonic lam- ina propria associated with reduced thickness of the colon wall. In addition, as shown in Figure 4C, while colon tissues stained with the Masson trichrome technique revealed increased amounts of collagen in the subepithelial and in deeper layers of the colonic lamina propria of untreated mice or scrambled ODN-treated mice, no increase in collagen deposition was observed in NF-кB decoy ODN-treated mice. As shown in Figure 4D, this reduction in collagen deposition was corroborated by the Sircol collagen assay: the amount of collagen after NF- $\kappa$ B decoy ODN treatment was significantly reduced to almost basal levels.

In additional studies of separate groups of mice, we evaluated the effect of NF-KB ODN treatment of BALB/c mice with chronic TNBS-colitis on in vitro cytokine production by lamina propria cells isolated on day 49. As shown in Figure 5A, cells from untreat- 

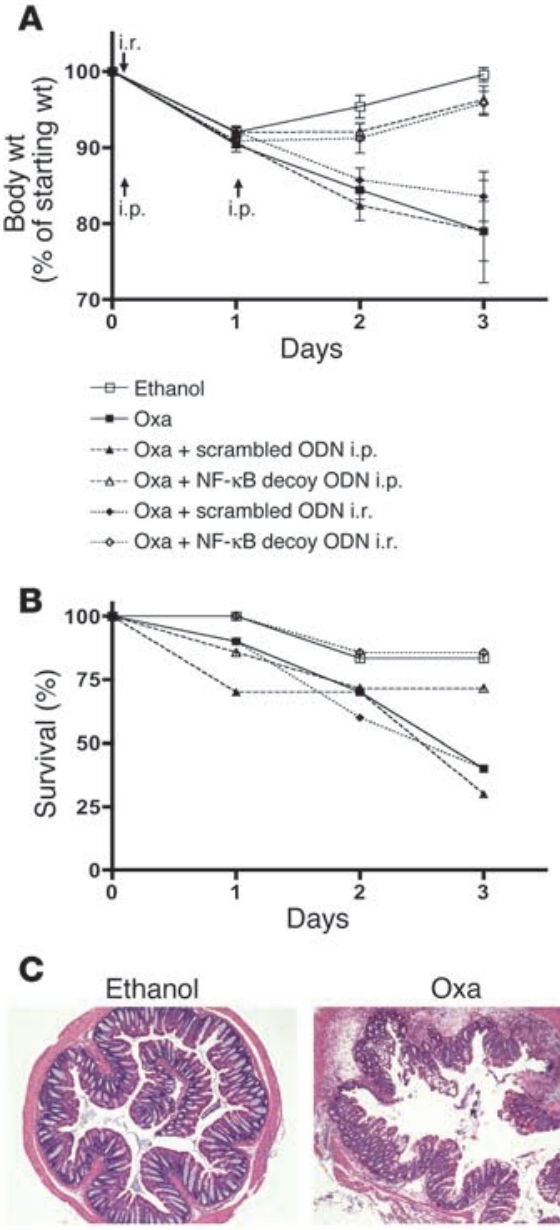

Oxa + scrambled ODN i.p.

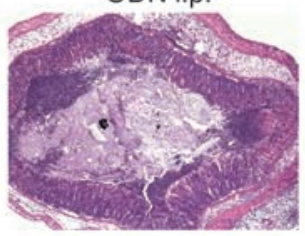

Oxa + scrambled ODN i.r.
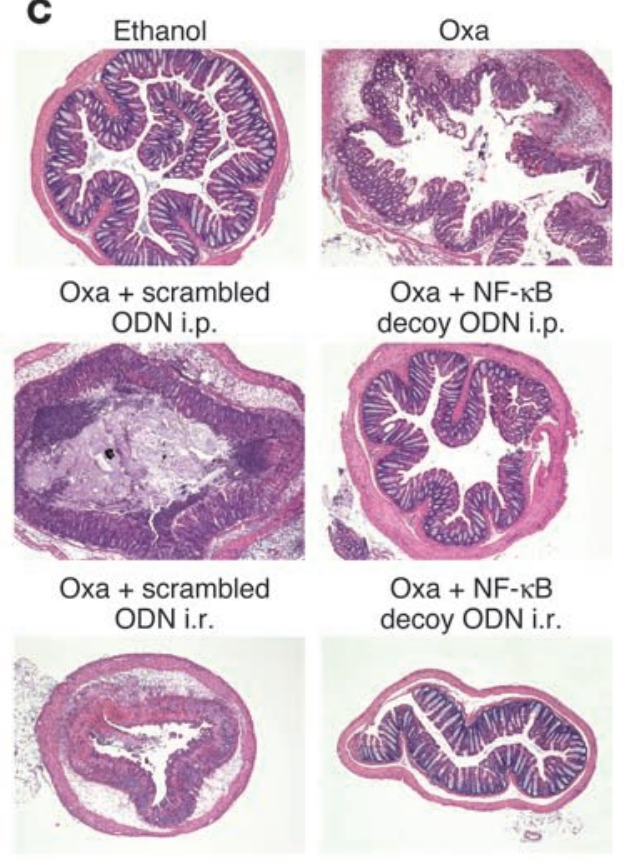

$\mathrm{Oxa}+\mathrm{NF}-\kappa \mathrm{B}$ decoy ODN i.p.

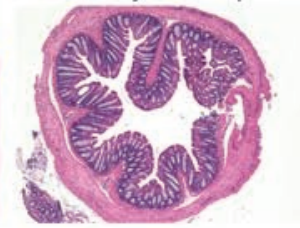

$\mathrm{Oxa}+\mathrm{NF}-\mathrm{kB}$ decoy ODN i.r.

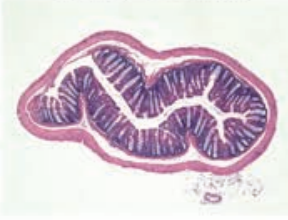

D

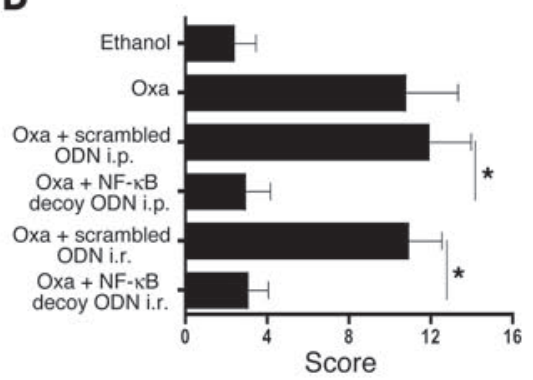

\section{E}

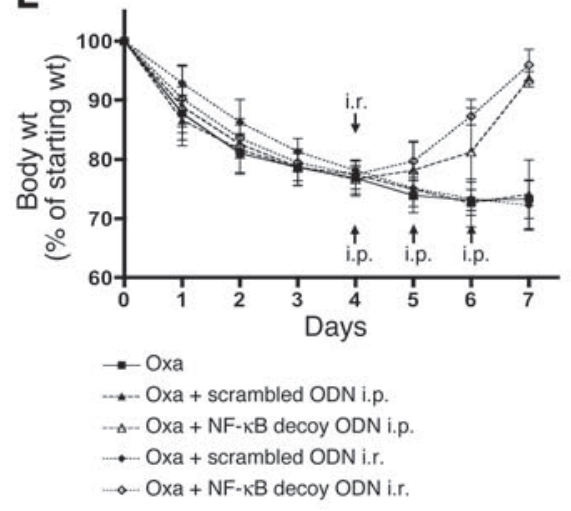

$\mathbf{F}$

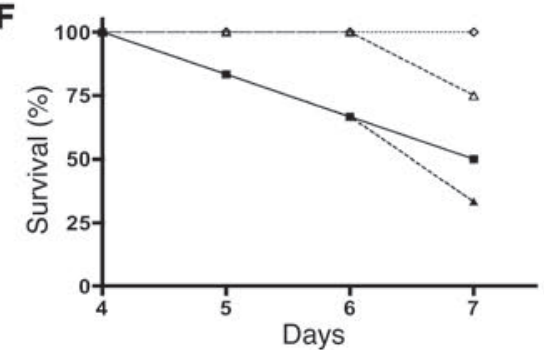

G Oxa

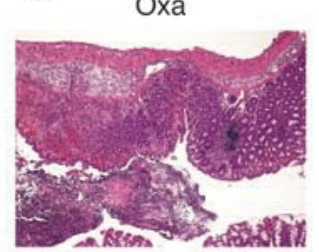

Oxa + scrambled ODN i.p.

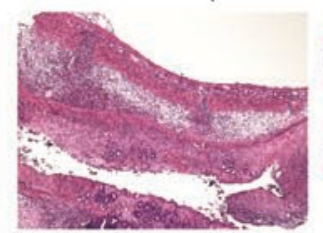

Oxa + scrambled ODN i.r.

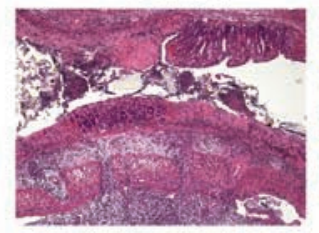
decoy ODN i.r.

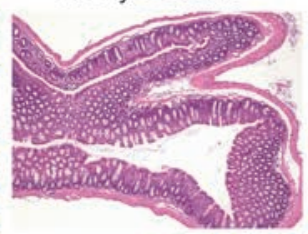

\section{Figure 6}

Prevention and treatment of oxazolone-colitis by administration of NF-KB decoy ODNs. (A-D) Oxazolone-colitis was induced by i.r. administration of oxazolone (Oxa) in ethanol. Mice were treated with NF-KB decoy ODNs (or scrambled ODNs) via an i.r. route (4 hours) or via an i.p. route (4 hours, 24 hours). Data shown are representative of 2 independent experiments. (A) Body weight as a percent of starting weight. Data shown are mean values \pm SD derived from at least 4 mice per group and are representative of 2 independent experiments. (B) Animal survival in percent until day 3 after oxazolone administration. (C) H\&E staining of representative colon cross-sections on day 3 after oxazolone administration. Magnification, $\times 5$. (D) Histological scores shown are mean values \pm SD derived from at least 4 mice per group. (E-H) Treatment of established oxazolone-colitis by administration of NF-кB decoy ODNs. Oxazolone-colitis was induced by i.r. administration of oxazolone in ethanol 4 days after skin presensitization with oxazolone. Mice were treated with NF-кB decoy ODNs (or scrambled ODNs) via an i.r. route (day 4) or via an i.p. route (days 4-6). (E) Body weight as a percent of starting weight. Data shown are mean values \pm SD derived from at least 3 mice per group. (F) Animal survival in percent until day 7 after oxazolone administration. (G) H\&E staining of representative colon longitudinal sections on day 7 after oxazolone administration. Magnification, $\times 5$. (H) Histological scores shown are mean values \pm SD derived from at least 3 mice per group. ${ }^{*} P<0.01$.
H

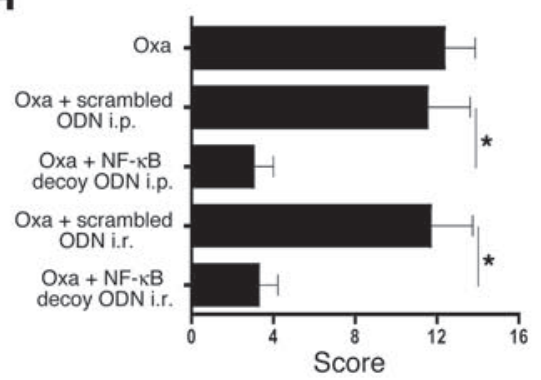


ed and scrambled ODN-treated mice with chronic TNBS-colitis produced elevated levels of Th1 cytokines, such as IL-12p70, IFN- $\gamma$, TNF- $\alpha$, IL-23, and IL-17. In addition, these cells produced markedly increased amounts of TGF- $\beta_{1}$ as well as increased amounts of Th2 cytokines, including modestly elevated amounts of IL-4 and markedly elevated amounts of IL-13. In contrast, cells from mice treated with NF-KB decoy ODNs produced only the basal amounts of these cytokines produced by control mice.

Finally, we evaluated the DNA-binding activity of the NF-кB subunit $\mathrm{p} 65$ in nuclear extracts of day 49 LPMCs from mice treated with scrambled ODNs or i.r. NF-KB decoy ODNs. As shown in

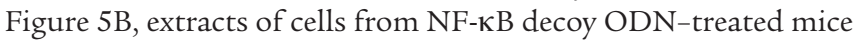
once again exhibited low levels of binding to plate-bound NF-кB consensus sequences in the TransFactor assay.

Taken together, these results show that NF-кB decoy ODNs can block the development of colitis as well as the development of fibrosis in a chronic model of TNBS-colitis. Given the fact that the development of fibrosis in this model is probably secondary to IL-13 secretion and induction of TGF- $\beta_{1}$ (see Discussion), this study shows that such treatment also blocks aspects of this inflammation mediated by Th2 cytokines.

Administration of $N F-\kappa B$ decoy ODNs packaged in HVJ-E prevents oxazolone-colitis and treats established oxazolone-colitis. In a further series of studies, we sought to determine the capacity of NF- $\mathrm{KB}$ decoy ODNs to treat the Th2 cytokine-mediated model of hapten-induced colitis that resembles ulcerative colitis, namely oxazolone-colitis. Accordingly, we induced acute oxazolone-colitis in C57BL/10 mice by i.r. administration of oxazolone in ethanol (see Methods) and then determined the course of colitis in untreated mice or mice treated on the day of oxazolone administration with either i.r. or i.p. NF-кB decoy ODNs or scrambled ODNs packaged in HVJ-E. As shown in Figure 6, A and B, untreated mice and mice treated with scrambled ODNs exhibited severe weight loss and a $50 \%$ mortality rate by day 3 after induction of oxazolonecolitis, whereas mice treated with NF-кB decoy ODNs by either route exhibited a weight equivalent to that of mice administered ethanol alone and a greatly reduced mortality. Moreover, as shown in Figure 6, C and D, these weight changes and survival figures correlated with histological examination of colons from mice in the various groups of acute oxazolone-colitis: untreated and scrambled ODN-treated mice exhibited high levels of inflammation associated with extensive epithelial cell ulceration, whereas NF-кB decoy ODN-treated mice exhibited virtually no inflammation.

In additional studies to explore the question of whether NF- $\mathrm{KB}$ decoy ODNs are able to reverse an established Th2 cytokine-mediated inflammation, we determined whether NF-кB decoy ODNs administration can treat a more prolonged form of oxazolonecolitis obtained by subjecting mice to skin presensitization with oxazolone prior to administration of i.r. oxazolone (5). To induce this form of oxazolone-colitis, we presensitized male C57BL/10 mice by painting the skin with $3 \%$ oxazolone in $100 \%$ ethanol and 4 days later administered $1.75 \%$ oxazolone in $47.5 \%$ ethanol i.r. Then, on day 4 after colitis induction, we administered 1 dose of NF-кB decoy or scrambled ODNs $(75 \mu \mathrm{g})$ by the i.r. route or 3 doses of these ODNs by the i.p. route on consecutive days (in both cases encapsulated in HVJ-E). Care was taken to ensure that the various experimental groups to be compared had lost equivalent amounts of weight. As shown in Figure 6, E and F, weight loss and mortality were severe in untreated presensitized oxazolone-colitis and in groups of presensitized oxazolone-colitis-administered scrambled
ODNs. However, administration of NF- $\mathrm{KB}$ decoy ODNs by either the i.p. or i.r. routes was effective in reversing this weight loss and mortality. In addition, as shown in Figure 6, G and $H$, this positive clinical effect was also evident in the histological examination and scoring of H\&E-stained colonic tissues.

Importantly, the effects of NF-KB decoy ODN administration were also reflected in the measurements of local cytokine secretion by cells extracted from the lamina propria and then stimulated ex vivo. Thus, as shown in Figure 7A, colonic lamina propria cells extracted on day 3 after induction of the acute oxazolone-colitis from untreated and scrambled ODN-treated mice produced high levels of both IL-4 and IL-13 upon stimulation, whereas cells from NF- $\kappa$ B decoy ODN-treated mice produced basal amounts of these cytokines. Similarly, as shown in Figure 7B, secretion of a Th2-associated chemokine, monocyte-derived chemokine/CCL22 (MDC/CCL22), was increased in colon cultures from untreated and scrambled ODN-treated mice but was undetectable in colon cultures of cells from NF-אB decoy ODN-treated mice. In contrast, as also shown in Figure 7A, whereas colonic LPMCs isolated from mice with ongoing acute inflammation (day 3 after instillation of oxazolone) secreted low levels of the antiinflammatory cytokine IL-10, colonic LPMCs from mice treated with NF- $\kappa B$ decoy ODNs exhibited greatly enhanced IL-10 secretion. This, plus the fact that IL-10 secretion is also increased in TNBS-colitis (Figure 3A) following treatment with NF- $\kappa \mathrm{B}$ decoy ODNs, indicates that such treatment may have a positive effect on the secretion of antiinflammatory cytokines, and this may be an additional mechanism of its antiinflammatory effect.

Similar results were obtained upon analysis of cytokine responses of cells isolated from the lamina propria of mice treated with NF-кB decoy ODNs after oxazolone-colitis had been established. Thus, as shown in Figure 7C, cells isolated on day 7, i.e., 3 days after initiation of treatment regimens on day 4 , cells from untreated mice or mice treated with scrambled ODNs produced large amounts of IL-13, whereas cells from mice administered NF-кB decoy ODNs produced baseline levels of this effector cytokine. In addition, cells from untreated mice or scrambled ODN-treated mice displayed low levels of IL-10, whereas cells from NF-кB decoy ODN-treated mice exhibited high levels of IL-10 secretion.

In further studies we determined the effect of NF-кB decoy ODN administration on NF- $\mathrm{KB}$ function in oxazolone-colitis using the TransFactor assay. As shown in Figure 7D, nuclear extracts of colonic LPMCs obtained on day 3 after instillation of oxazolone from untreated or scrambled ODN-treated mice exhibited high levels of binding of p65 to plate-bound NF-кB consensus sequences, whereas equivalent extracts of LPMCs from NF-кB decoy ODN-treated mice exhibited low levels of binding. Thus, as in the case of the TNBS-induced inflammatory states, NF- $\mathrm{B}$ decoy ODN administration to mice with oxazoloneinduced inflammation inhibits binding of NF- $\kappa B$ components to NF- $\kappa \mathrm{B}$ consensus sequences.

Finally, to establish a theoretical basis for the mechanism by which NF-кB decoy ODN administration inhibits Th2 inflammation, we determined whether such administration downregulates the expression of a NF-кB-dependent protein necessary for the induction of

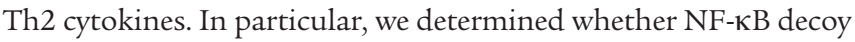
ODN administration affects the expression of IFN regulatory factor 4 (IRF4), an NF-אB-dependent intracellular protein that has been shown to be necessary for the induction of Th2 cytokines $(35,36)$. Accordingly, we obtained colonic LPMCs from mice 3 days after i.r. 

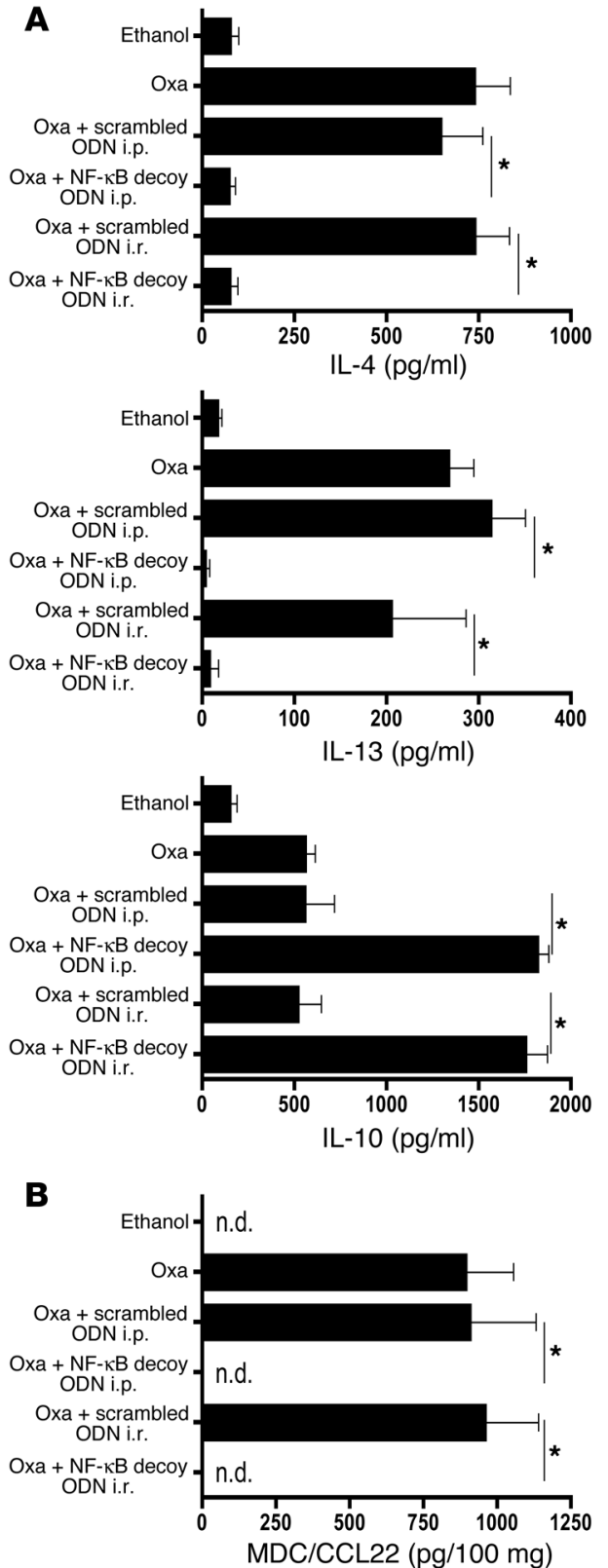
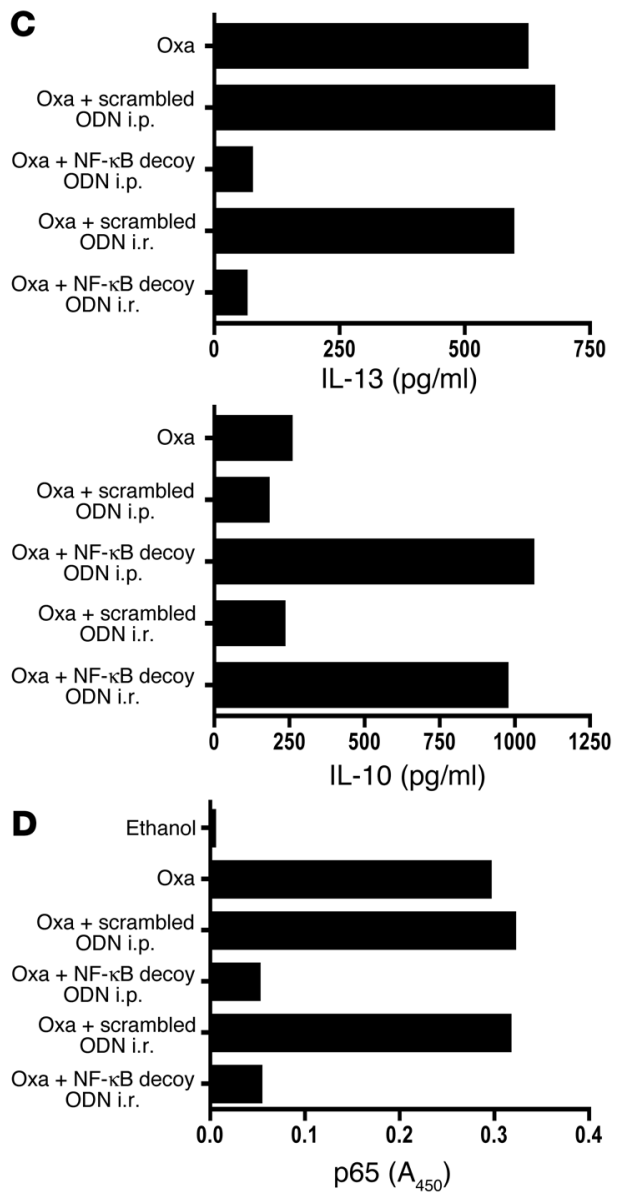

$\mathbf{E}$

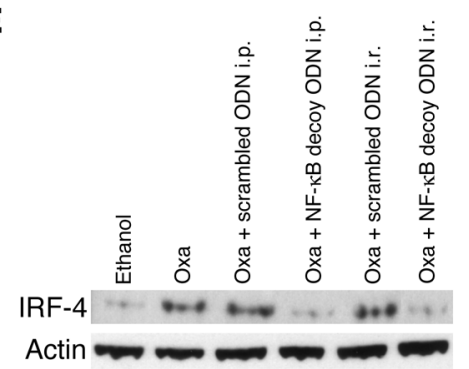

\section{Figure 7}

Prevention and treatment of oxazolone-colitis with NF-kB decoy ODNs - effect on cytokine production and intracellular proteins. (A) Cytokine production in cultures of colonic LPMCs isolated on day 3 after oxazolone administration. Cytokine concentrations were determined in culture supernatant by ELISA. Data shown are mean values \pm SD and are representative of 2 independent experiments. (B) Monocyte-derived chemokine/CCL22 (MDC/CCL22) production in ex vivo colon cultures isolated on day 3 after oxazolone administration; chemokine concentrations in the culture supernatant were determined by ELISA. Data shown are mean values \pm SD and are representative of 2 independent experiments. (C) Cytokine production in cultures of colonic LPMCs on day 7 after oxazolone administration and day 3 after oligonucleotide administration; each culture contained cells pooled from at least 3 mice; cytokine concentrations were determined in culture supernatant by ELISA. (D) DNA-binding activity of p65 in nuclear extracts of cells derived from lamina propria on day 3 after oxazolone administration measured in nuclear extracts from colonic lamina propria cells by TransFactor assay. (E) IRF4 protein expression is reduced in colonic LPMCs. Total colonic LPMC lysates were analyzed by Western blotting on day 3 after oxazolone administration. ${ }^{\star} P<0.01$. n.d., not detectable. oxazolone administration and then subjected lysates from these cells to Western blot analysis for the detection of IRF4. As shown in Figure 7E, LPMCs from mice treated with NF-кB decoy ODNs exhibited an IRF4 protein band with greatly reduced intensity when compared with LPMCs cells from control mice. These studies strongly suggest that at least 1 mechanism of action of NF- $\kappa B$ decoy ODNs in the inhibition of Th2 inflammation is the inhibition of NF- $\kappa \mathrm{B}-$ dependent proteins necessary for Th2 differentiation.

Taken together, these studies show that NF- $\kappa B$ decoy ODN administration has profound effects on Th2 models of colonic inflammation as well as on Th1 models.

Administration of $N F-\kappa B$ decoy $O D N$ s via the i.r. route suppresses local

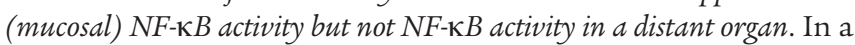
final series of studies, we determined the effects of i.r. and i.p. NF- $\kappa B$ decoy ODN administration on NF- $\mathrm{KB}$ activation outside of the colon. Accordingly, mice administered i.r. TNBS to induce TNBS- colitis were treated with NF-אB decoy ODNs by i.r. (4 hours after TNBS administration) or i.p. (4 hours, 1 day, and 2 days after TNBS administration) routes. Then, on day 5 after TNBS induction, nuclear extracts from mononuclear cells isolated from the colonic lamina propria, spleen, and liver were obtained. The extracts were then subjected to a TransFactor assay to determine p65 DNA-binding activity. As shown in Figure 8, whereas i.p. administration of NF- $\kappa$ B decoy ODNs led to decreased p 65 activity in cells from all 3 organs, i.r. administration led to greatly decreased activity in colonic lamina propria cells but not in splenic or hepatic cells. These studies thus show that local administration of NF-кB decoy ODNs has little effect on extraintestinal mononuclear cells.

\section{Discussion}

In this study, we determined whether blockade of NF- $\mathrm{B}$ transcriptional activity by administration of decoy ODNs correspond- 

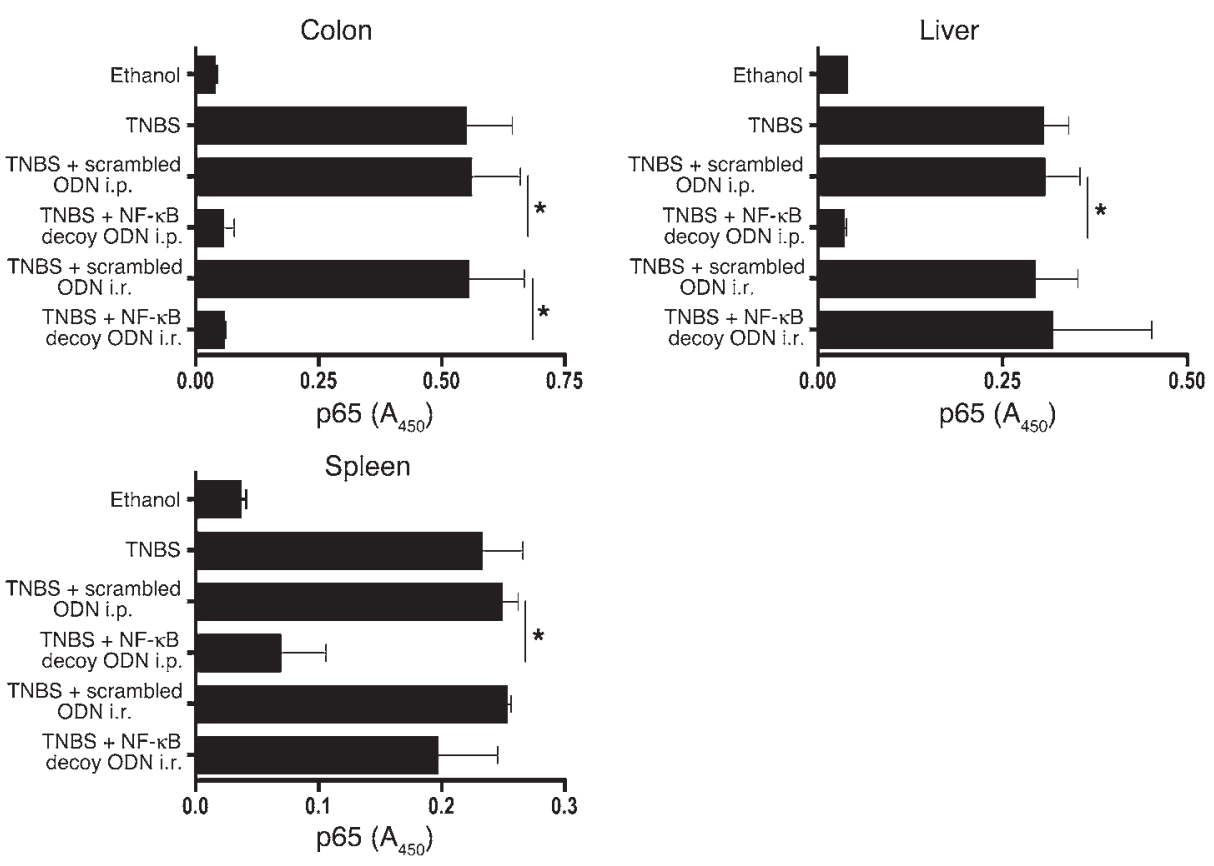

ing to the consensus binding site of the major NF- $\mathrm{kB}$ components and encapsulated in a viral envelope derived from HVJ could prevent and/or treat experimental models of inflammatory bowel diseases. Indeed, we found that such treatment was also very effective in preventing both the development of a Th1-mediated colitis (TNBS-colitis in C57BL/10 mice) as well as a Th2-mediated colitis (oxazolone-colitis in C57BL/10 mice) and thus appear to be comparable to the effects of administration of Abs (as shown in previous studies) capable of neutralizing the cytokines that drive these inflammations: anti-IL-12p40 in the case of TNBS-colitis and anti-IL- 4 or soluble IL- $13 \mathrm{R} \alpha_{2}-\mathrm{Fc}$ in the case of oxazolonecolitis $(5,13,15)$. In addition, such treatment was equally effective in reversing the course of an already-established TNBS-colitis both in an acute model induced in C57BL/10 mice and a chronic model induced in BALB/c mice. Since anti-IL-12p40 treatment of TNBS-colitis (and other experimental colitides) has now been at least partially replicated in patients with Crohn disease (8), the high efficacy of treatment of TNBS-colitis with NF-кB decoy ODNs must now be seriously considered as a possible treatment of some forms of human Crohn disease and as a possible treatment of human ulcerative colitis.

The favorable treatment outcomes we obtained in these studies can be attributed to several factors. First, we took advantage of the fact that exogenous DNA such as NF-кB decoy ODNs can be encapsulated in a viral vesicle formed by inactivated HVJ, a Sendai virus, and that these vesicles can bind to and fuse with cell membranes, thus releasing the encapsulated DNA into the cell cytoplasm $(30,33,34)$. The efficacy of this cell transfection method was shown in in vitro studies in which we observed that primary mouse $T$ cells can be transfected with plasmid constructs packaged in HVJ-E at an efficiency of greater than 90\% (data not shown). Perhaps more importantly, the efficacy of this method was also shown in vivo, where it was observed that administration of the NF-KB decoy ODNs to mice with the various types of TNBScolitis studied here resolved the inflammation and led to virtually complete disappearance of NF- $\mathrm{KB}$ binding activity for all 5

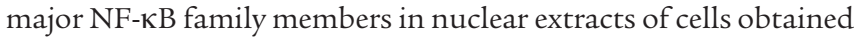
from colonic tissue. Of interest, we were able to deliver sufficient amounts of decoy ODNs to cells with unmodified HVJ-E, rather than cationic liposome HVJ complexes that have been shown to be highly efficient delivery vehicles in previous in vitro transfection studies (37). However, such complexes are tedious to assemble, inherently unstable, and do not readily target many types of cells in vivo unless fine tuned vis-à-vis phospholipid content. Finally, it should be noted that the NF-KB decoy ODNs had more potent effects when delivered directly to the site of inflammation by i.r. administration, since a greater amount of decoy was needed for effective systemic administration. Such i.r. application of decoy ODNs was also advantageous in that it led to less effect of decoy ODNs on mononuclear cells in extraintestinal organs (liver and spleen) than was the case with i.p. administration of decoy. This strongly suggests that administration of decoy ODNs by the i.r. route would not give rise to systemic side effects consequent to NF- $\kappa \mathrm{B}$ blockade in the immune system as a whole.

Second, we found that, as in the case of treatment with anti-IL$12 \mathrm{p} 40$, treatment with NF-KB decoy ODNs led to increased apoptosis of $\mathrm{CD}^{+} \mathrm{T}$ cells, as detected by flow cytometric enumeration of annexin $\mathrm{V}$-stained cells in populations of $\mathrm{T}$ cells extracted from the lamina propria (13). The mechanism of apoptosis induction following inhibition of NF-KB signaling is probably multifactored. One possible mechanism involves the fact that activation of NF- $\mathrm{KB}$ leads to the synthesis of proteins that block Jun $\mathrm{N}$-terminal kinase, an enzyme utilized by TNF- $\alpha$ to induce apoptosis $(38,39)$. Thus, the inhibition of NF- $\mathrm{KB}$ signaling by NF-KB decoy ODNs leads to relief from this block and facilitation of TNF- $\alpha$-induced apoptosis. Another possible mechanism is related to the fact that NF- $\kappa B$ signaling leads to the synthesis of inhibitor of apoptosis proteins, a family of as-yet poorly understood antiapoptotic proteins (40). Finally, it is important to recall that NF-KB is necessary for the production of IL-12, a cytokine that has significant antiapoptotic effects on Th1 T cells; thus, by shutting down IL-12 production, NF-кB decoy ODNs lead to apoptosis of Th1 cells. Regardless of 
the mechanism by which decoy ODNs induce apoptosis, the very fact that such apoptosis occurs and leads to the loss of $\mathrm{T}$ effector cells suggests that treatment with NF-KB decoy ODNs is likely to have a durable therapeutic effect.

Third, the design of the decoy ODNs used in these studies allowed the best possible chance of inhibiting the inflammation-

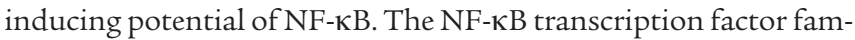
ily consists of 5 different subunits, c-Rel, p65, RelB, p50, and p52, each capable of forming homodimers and heterodimers and each having in common an amino-terminal region containing dimerization, nuclear-localization, and DNA-binding domains. Importantly, the latter DNA-binding domains bind to a consensus binding site on target promoters; thus, a decoy ODN that mimics the sequence of the consensus binding site, such as that used in these studies, inhibits binding and transcriptional activity by all major components of the NF-кB family. The importance of such broadspectrum inhibition in an inflammatory process like that occurring in inflammatory bowel disease is inherent in the fact that despite the existence of a consensus binding sequence, the role of NF- $\kappa \mathrm{B}$ transactivation cannot be assumed to be due to any specific NF-кB family member. Thus, while antisense ODNs that are specific for $\mathrm{p} 65$ have been shown to be effective in the treatment of TNBS-colitis, IL-12 production has been shown to be highly dependent on c-Rel $(16,41)$. Finally, it is important to mention that certain NF- $\kappa \mathrm{B}$ components, especially p50 homodimers, can act as transcriptional repressors because they bind to consensus binding sequences but lack carboxyterminal domains that bind to nonhomologous transactivation sites (42). Thus, the fact that

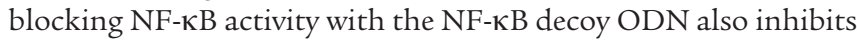
p50 DNA-binding activity could conceivable have a proinflammatory effect. However, since the decoy ODNs used here inhibit all major components, it would theoretically inhibit both the positive and negative effects of NF-кB components and have a net antiinflammatory effect. This view is strongly supported by the effects of NF-кB decoy ODNs studied here as well as in previous studies of experimental inflammations of various types (43-45).

A fourth and final reason for the success of the NF- $\kappa \mathrm{B}$ decoy ODN treatment is that the main cytokine drivers of the $\mathrm{T}$ cellmediated response in the inflammations are, as already implied above, dependent on NF- $\mathrm{KB}$ transcriptional activation of the relevant cytokine genes. Thus, in the case of the Th1-mediated inflammation studied, it is now well established that not only the p35 component of IL-12, but also the p40 component of IL-12/IL-23 as well as IL-17 are dependent on NF- $\mathrm{KB}$ transcriptional activity $(20-23,46)$. Likewise, in the case of the Th2-mediated inflammation studied, NF- $\mathrm{KB}$ is needed for the activation of a number of genes that are necessary for IL- 4 and IL-13 production, including IL-2 and IRF4, the latter a factor induced by TLR stimulation and the subsequent production of type I interferons $(35,36)$.

In recent years a number of quite disparate agents that inhibit NF- $\mathrm{B}$ have been shown to have positive effects on experimental mucosal inflammation. These include agents derived from plants (catalposide, fucoidan, or curcumin) (47-49), low-molecular-weight molecules such as the MAPKs and RICK inhibitor (SB203580), the rho kinase inhibitor (Y27632), the PPAR $\gamma$ ligand (pioglitazone), and gliotoxin (50-53). For the most part, these inhibitors have been tested in studies of either dextran sulphate sodium-induced colitis or hapten-induced colitis, in which their capacities to prevent mucosal inflammatory disease were assessed rather than their capacities to reverse established inflammatory disease, a more stringent test. In addition, these inhibitors were administered via a systemic route, and the specificity of their inhibitory effects for NF- $\mathrm{KB}$ was not assessed; thus they could have significant side effects. For example, SB203580 and curcumin not only inhibit NF-кB activation but also activation of the MAPK pathway. In addition, the rho kinase inhibitor Y27632, in that it has activity in a number of rather different disorders, such as hypertension, Alzheimer disease, bronchial asthma, and coronary heart disease, is likely to affect several signaling pathways (54-57). Finally, gliotoxin is a known inducer of cellular apoptosis and can cause free radical damage $(58,59)$. In contrast to these moreor-less nonspecific NF- $\mathrm{KB}$ inhibitors, the previously studied p65 antisense phosphorothioate ODN NF- $\mathrm{BB}$ inhibitor is as specific

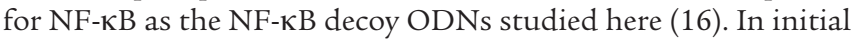
studies that were in fact the first studies of an NF- $\kappa B$ inhibitor in experimental colitis (16), this agent was shown to be an effective preventative treatment of an acute model of TNBS-colitis. In later, very recent studies, the same agent was again shown to be an effective preventive agent in a chronic model of TNBS-colitis, the TNBS-colitis induced in BALB/c mice, but in this case, it was only partially effective as a treatment agent (27). The reason for this partial effect may be 2-fold. First, since it inhibits p 65 mRNA synthesis and not other NF- $\mathrm{KB}$ components, it only partially blocks NF-кB signaling. Second, since it was delivered as naked ODNs rather than a nucleotide encapsulated in a viral envelop that has a high capacity to penetrate mammalian cells, it may not have been efficiently delivered to key inflammatory cells.

One of the important features of the antiinflammatory effects of NF-кB decoy ODNs packaged in HVJ-E was its capacity to prevent the development of and to treat an already established inflammation occurring in a Th2-mediated mucosal inflammation. This was first shown in the chronic TNBS-colitis established in $\mathrm{BALB} / \mathrm{c}$ mice that begins as a Th1 inflammation and then gradually evolves into a mixed Th1/Th2 inflammation in which Th2 cytokines, especially IL-13, are secreted along with Th1 cytokines. Thus, the fact that administration of NF-KB decoy ODNs packaged in HVJ-E led to resolution of inflammation after the colitis had evolved into a mixed Th1/Th2 inflammation provided initial evidence that this treatment was also relevant to a Th2-driven inflammatory process.

A second and perhaps more definitive body of evidence relevant to the efficacy of NF- $\mathrm{KB}$ decoy ODN treatment of a Th2 colitis was obtained with its use in oxazolone-colitis. In previous studies it has been shown that this model of colitis is due to the induction of NKT cells that produce IL-13 and that administration of agents that eliminate NKT cells and/or block IL-13 function ameliorate the disease (5). Thus, the demonstration in this study that NF-кB decoy ODN administration can both prevent nascent oxazolone-colitis and reverse established oxazolone-colitis provides strong evidence that decoy administration is in fact an effective therapeutic agent in Th2 inflammation. In this context, it should be noted that oxazolone-colitis bears a histologic resemblance to ulcerative colitis, and, indeed, the human disease is also characterized by the increased production of IL-13 by NKT cells. Thus, NF-кB decoy ODN treatment may prove useful in the treatment of the ulcerative colitis, particularly in light of the fact that this disease is limited to the colon and thus can be effectively treated with an agent administered by the i.r. route.

The mechanism of action of the NF-KB decoy ODNs in oxazolone-colitis (and in other forms of Th2 colitis) is probably mul- 
tifactorial, but it is reasonable to assume that several cytokines, chemokines, or intracellular factors necessary for the generation of the Th2 response are dependent on NF- $\mathrm{KB}$ signaling and thus susceptible to blockade by NF-KB decoy ODNs. The possible cytokine/ chemokine targets of the decoy include IL-2, a cytokine that has recently been shown to play a role in the initiation of Th $2 \mathrm{~T}$ cell differentiation, as well as MDC/CCL22, a TNF- $\alpha$-dependent chemokine that attracts Th2 $\mathrm{T}$ cells to inflammatory sites (60-62). In the same vein, the possible intracellular signaling factors that are decoy targets include IRF4 and IRF5, factors induced by TLR signaling that have been shown to be necessary for Th2 $\mathrm{T}$ cell differentiation and Th2-mediated inflammation $(35,36)$. In partial confirmation of this latter supposition, we were able to show that NF-KB decoy ODN treatment exerts a downregulatory effect on the expression of IRF4. Finally, it should be noted that while the development of NKT cells is known to be critically dependent on the NF-KB component RelB, it is unlikely that NF-KB decoy ODNs prevented acute oxazolone-colitis through the inhibition NKT cell development, since the decoy ODN effect was too rapid (63). It is possible, however, that human ulcerative colitis would be ameliorated by blockade of RelB-dependent NKT cell development through repeated administration of NF- $\mathrm{KB}$ decoy ODNs.

Yet another important feature of NF- $\mathrm{kB}$ decoy ODN treatment is its capacity to prevent the development of fibrosis that invariably occurs in the chronic TNBS model induced in BALB/c mice. Such fibrosis is also a constant complication of long-standing IBD and one that can lead to some of the direst IBD symptoms, such as loss of gut motility and obstruction. In the chronic TNBS model studied here, fibrosis becomes evident after 6 weeks of TNBS administration and is marked by increasing collagen deposition in the subepithelial layer as well as in the lamina propria associated with

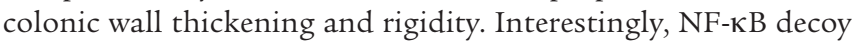
ODN treatment, even when begun well after the establishment of chronic colitis, could effectively minimize collagen deposition, suggesting that decoy ODN treatment could block fibrosis in IBD even after a long period of inflammation. A similar result was noted in the aforementioned treatment of mice with chronic TNBS-colitis with $\mathrm{p} 65$ antisense ODNs. As to the mechanism of this antifibrotic effect, it is now known that TGF- $\beta_{1}$, an important fibrogenic factor, is induced by IL-13, and we have found in unpublished studies that such induction depends on NF-KB-dependent IL-13 signaling (64). Thus, it is likely that the antifibrotic effect of the decoy resulted from its ability to indirectly downregulate TGF- $\beta_{1}$ through its ability to prevent IL-13 secretion.

In summary, these studies strongly suggest that NF- $\mathrm{\kappa B}$ decoy ODNs targeting the consensus NF-KB binding site and encapsulated in an HVJ-E represent a very potent approach to the treatment of experimental mucosal inflammation. They thus indicate that not only the cytokines responsible for initiation of mucosal inflammation but also those responsible for the persistence of inflammation are dependent on NF-kB. These mouse studies set the stage for clinical studies of the efficacy of NF-KB decoy ODNs in patients with IBD, particularly those with colonic inflammation that can readily be treated with i.r. decoy ODNs.

\section{Methods}

Mice. Male C57BL/10 mice (6-8 weeks old) were used in studies of both the prevention and treatment of TNBS-colitis and oxazolone-colitis. Female $\mathrm{BALB} / \mathrm{c}$ mice (8-10 weeks old) were used in studies of a chronic form of TNBS-colitis. All mice were obtained from Jackson Laboratory and were maintained in the National Institute of Allergy and Infectious Diseases (NIAID) animal holding facilities. Animal use adhered to NIH Laboratory Animal Care Guidelines, and all animal experiments were approved by the NIAID Animal Care and Use Committee review board.

Induction of colitis. Mice were lightly anesthetized with isoflurane and then administered a haptenating agent (either TNBS or oxazolone dissolved in ethanol) i.r. via a 3.5 French (F) catheter equipped with a 1-ml syringe; the catheter was advanced into the rectum until the tip was $4 \mathrm{~cm}$ proximal to the anal verge, at which time the haptenating agent was administered in a total volume of $150 \mu$ l. To ensure distribution of the haptenating agent within the entire colon and cecum, mice were held in a vertical position for 30 seconds after the i.r. injection. Control mice were administered an ethanol solution without haptenating agent using the same technique. $3.75 \mathrm{mg}$ TNBS (Sigma-Aldrich) in 50\% ethanol was administered for studies of prevention of acute TNBS-colitis, $3 \mathrm{mg}$ TNBS in $45 \%$ ethanol for studies of treatment of established acute TNBS-induced colitis, and 1.5-2.5 mg TNBS (in increasing doses) in $45 \%$ ethanol was administered each week for studies of treatment of chronic TNBS-induced colitis. Six milligrams oxazolone (Sigma-Aldrich) in $47.5 \%$ ethanol was administered for studies of prevention of acute oxazolonecolitis. To induce a longer-lasting form of oxazolone-colitis, we presensitized mice by applying a $3 \%$ solution of oxazolone in $100 \%$ ethanol to a shaved $2 \times 2 \mathrm{~cm}$ field of the abdominal skin 4 days prior to i.r. administration of $1.75 \%$ oxazolone in $47.5 \%$ ethanol.

Preparation of HVJ-E vector and its loading with ODNs. HVJ-E vector was prepared as previously described (41). In brief, suspended Sendai virus $(25,600$ hemagglutinating units; AnGes MG) was inactivated by $\beta$-propiolactone followed by ultraviolet irradiation and purified by column chromatography. The HVJ-E thus obtained was mixed with $37.5 \mu$ l of protamine sulfate $(1 \mathrm{mg} / \mathrm{ml})$ and then incubated for 10 minutes on ice. Insertion of ODNs into the vector was accomplished using a packaging technique that allowed direct insertion of ODNs into the viral envelope. This involved mixing DNA $(1 \mathrm{mg} / 100 \mu \mathrm{l})$ and $13.8 \mu \mathrm{l}$ of $3 \%$ Triton X-100 with the HVJ-E and then incubating the resultant mixture for 15 minutes on ice. Finally, the HVJ-E-ODNs were centrifuged at $15,000 \mathrm{~g}$ for 15 minutes and resuspended in $500 \mu \mathrm{l}$ of PBS containing $72 \mu \mathrm{g}$ of protamine sulfate.

Decoy ODNs. Double-stranded DNA ODNs with sequences corresponding to the consensus NF- $\mathrm{\kappa B}$ combining site or scrambled were provided by AnGes MG. Seventy-five micrograms of NF-אB decoy or scrambled ODNs were administered during each in vivo treatment. The following sequences were used: NF-кB decoy ODNs, 5'-CCTTGAAGGGATTTCCCTCC-3' and 3'-GGAACTTCCCTAAAGGGAGG-5'; scrambled decoy ODNs, 5-CATGTCGTCACTGCGCTCAT-3' and 3'-GTACAGCAGTGACGCGAGTA-5'.

ELISA. Cytokine protein concentrations in culture supernatants were measured by ELISA kits according to the manufacturer's instructions. Isolated colonic LPMCs were stimulated for 48 hours. To determine IFN- $\gamma$, IL-4, and IL-13 protein concentrations, cells were stimulated with plate-bound anti-CD3 Ab and soluble anti-CD28 Ab (BD Biosciences Pharmingen). For measurement of IL- 12 p70, TNF- $\alpha$, and TGF- $\beta_{1}$ colonic LPMCs were stimulated 48 hours with Staphylococcus aureus Cowan I (EMD Biosciences) and IFN- $\gamma$ (R\&D Systems). IL-23 was determined after 48 hours stimulation of colonic LPMCs with peptidoglycan (Sigma-Aldrich). ELISA kits for IFN- $\gamma$, IL-4, IL-12p70, TNF- $\alpha$, and IL-10 were purchased from BD Biosciences - Pharmingen and for TGF- $\beta_{1}$ from BioSource International and IL-23 from eBioscience.

Flow cytometry. Colonic LPMCs were stained with annexin V, propidium iodide, anti-CD4 Ab (BD Biosciences - Pharmingen). Nonspecific binding of Abs was blocked by preincubation with Fc Block (BD Biosciences - Pharmingen). Cells were acquired using a BD FACScan and analyzed utilizing FlowJo software. 
Collagen assay. Colons of TNBS-treated mice were harvested on day 49 and homogenized in $0.5 \mathrm{M}$ acetic acid containing $1 \mathrm{mg}$ pepsin (at a concentration of $10 \mathrm{mg}$ tissue $/ 10 \mathrm{ml}$ of acetic acid solution). The resulting mixture was then incubated for 24 hours at $4{ }^{\circ} \mathrm{C}$ with stirring. Colon collagen content was determined by assaying total soluble collagen using the Sircol Collagen Assay kit (Biocolor Ltd.) (65). Acid soluble type I collagen supplied with the kit was used to generate a standard curve.

Assay of activated NF- $\mathrm{\kappa B}$ components. Nuclear extracts from colonic LPMCs were obtained using the TransFactor Extract Kit (Active Motif). The extracts were then tested for DNA-binding activity using the NF- $\mathrm{KB}$ TransFactor Kit (BD Biosciences - Clontech) according to the manufacturer's instructions. In brief, nuclear extract $(15-30 \mu \mathrm{g})$ was applied to each well coated with NF-KB consensus ODNs, and then wells were incubated with specific Abs for each of the NF-kB subunits followed by HRP-labeled secondary Abs (41). After color development with TMB substrate was stopped by adding $\mathrm{H}_{2} \mathrm{SO}_{4}$, absorbance was measured at $450 \mathrm{~nm}$ wavelength.

Western blot analysis. Total cell lysates from colonic LPMCs were subjected to SDS-PAGE, and the separated proteins thus obtained were transferred to a nitrocellulose membrane. A protein band for mouse IRF4 was detected by incubation with a polyclonal goat anti-IRF4 Ab (Santa Cruz Biotechnology Inc.) followed by incubation with HRP-conjugated anti-goat IgG (Zymed Laboratories Inc.). Membranes were developed with SuperSignal West Pico Chemiluminescent Substrate (Pierce Biotechnology Inc.) and exposed to x-ray film.

Histological examination. Colons were fixed in $10 \%$ buffered formalin and embedded in paraffin. Paraffin-embedded colon sections were cut and then stained with H\&E or by the Masson's trichrome method. To visualize apoptotic cells, in situ paraffin sections of colonic tissue were subjected to TUNEL staining (66). TUNEL-positive cells were visualized by fuchsin red, and sections were counterstained with hematoxylin (Sigma-Aldrich). For calculation of inflammation indices in treated and control group of mice, the $\mathrm{H} \& \mathrm{E}$ sections were read by investigators blinded to the experimental protocol and evaluated according to formerly published scoring systems for TNBS-colitis and oxazolone-colitis $(13,67)$.

Statistics. Statistical differences were assessed using the 2-tailed Student's $t$ test. $P$ values less than 0.05 were considered statistically significant.

\section{Acknowledgments}

This research was supported by the Intramural Research Program of the NIH, NIAID, and by the Material Cooperative Research and Development Agreement (MCRADA) with AnGes, MG Inc. and GenomIdea Inc.

Received for publication February 17, 2005, and accepted in revised form July 26, 2005.

Address correspondence to: Stefan Fichtner-Feigl, Mucosal Immunity Section, Laboratory of Host Defenses, National Institute of Allergy and Infectious Diseases, National Institutes of Health, Building 10-Clinical Research Center 5W-3864, 10 Center Drive, Bethesda, Maryland 20892, USA. Phone: (301) 496-9662; Fax: (301) 402-2240; E-mail: stefan.fichtner@klinik.uni-regensburg.de.
1. Podolsky, D.K. 2002. Inflammatory bowel disease. N. Engl. J. Med. 347:417-429.

2. Bouma, G., and Strober, W. 2003. The immunological and genetic basis of inflammatory bowel disease. Nat. Rev. Immunol. 3:521-533.

3. Sartor, R.B. 2004. Therapeutic manipulation of the enteric microflora in inflammatory bowel diseases: antibiotics, probiotics, and prebiotics. Gastroenterology. 126:1620-1633.

4. Maeda, S., et al. 2005. Nod2 mutation in Crohn's disease potentiates NF- $\kappa \mathrm{B}$ activity and IL- $1 \beta$ processing. Science. 307:734-738.

5. Heller, F., Fuss, I.J., Nieuwenhuis, E.E., Blumberg, R.S., and Strober, W. 2002. Oxazolone colitis, a Th2 colitis model resembling ulcerative colitis, is mediated by IL-13-producing NK-T cells. Immunity. 17:629-638.

6. Uhlig, H.H., and Powrie, F. 2003. Dendritic cells and the intestinal bacterial flora: a role for localized mucosal immune responses. J. Clin. Invest. 112:648-651. doi:10.1172/JCI200319545.

7. Monteleone, G., et al. 1997. Interleukin 12 is expressed and actively released by Crohn's disease intestinal lamina propria mononuclear cells. Gastroenterology. 112:1169-1178.

8. Mannon, P.J., et al. 2004. Anti-interleukin-12 antibody for active Crohn's disease. N. Engl. J. Med. 351:2069-2079.

9. Fuss, I.J., et al. 2004. Nonclassical CD1d-restricted NK T cells that produce IL- 13 characterize an atypical Th2 response in ulcerative colitis. J. Clin. Invest. 113:1490-1497. doi:10.1172/JCI200419836.

10. Schmidt, C., et al. 2005. Expression of interleukin-12-related cytokine transcripts in inflammatory bowel disease: elevated interleukin-23p19 and interleukin-27p28 in Crohn's disease but not in ulcerative colitis. Inflamm. Bowel Dis. 11:16-23.

11. Neurath, M.F., Fuss, I., Kelsall, B.L., Stuber, E., and Strober, W. 1995. Antibodies to interleukin 12 abrogate established experimental colitis in mice. J. Exp. Med. 182:1281-1290.

12. Kitani, A., et al. 2000. Treatment of experimental (Trinitrobenzene sulfonic acid) colitis by intrana- sal administration of transforming growth factor (TGF)-beta1 plasmid: TGF-beta1-mediated suppression of Thelper cell type 1 response occurs by interleukin (IL)-10 induction and IL-12 receptor beta2 chain downregulation. J. Exp. Med. 192:41-52.

13. Fuss, I.J., et al. 1999. Anti-interleukin 12 treatment regulates apoptosis of Th1 T cells in experimental colitis in mice. Gastroenterology. 117:1078-1088.

14. Strober, W., Fuss, I.J., and Blumberg, R.S. 2002. The immunology of mucosal models of inflammation. Annu. Rev. Immunol. 20:495-549.

15. Boirivant, M., Fuss, I.J., Chu, A., and Strober, W. 1998. Oxazolone colitis: a murine model of $T$ helper cell type 2 colitis treatable with antibodies to interleukin 4. J. Exp. Med. 188:1929-1939.

16. Neurath, M.F., Pettersson, S., Meyer zum Buschenfelde, K.H., and Strober, W. 1996. Local administration of antisense phosphorothioate oligonucleotides to the 655 subunit of NF-kappa B abrogates established experimental colitis in mice. Nat. Med. 2:998-1004.

17. Neurath, M.F., et al. 1998. Cytokine gene transcription by NF-kappa B family members in patients with inflammatory bowel disease. Ann. N. Y. Acad. Sci. 859:149-159.

18. Schreiber, S., Nikolaus, S., and Hampe, J. 1998. Activation of nuclear factor kappa B inflammatory bowel disease. Gut. 42:477-484.

19. Bantel, H., et al. 2000. Mesalazine inhibits activation of transcription factor NF-kappaB in inflamed mucosa of patients with ulcerative colitis. Am. J. Gastroenterol. 95:3452-3457.

20. Plevy, S.E., Gemberling, J.H., Hsu, S., Dorner, A.J., and Smale, S.T. 1997. Multiple control elements mediate activation of the murine and human interleukin 12 p40 promoters: evidence of functional synergy between C/EBP and Rel proteins. Mol. Cell. Biol. 17:4572-4588.

21. Becker, C., et al. 2003. Constitutive p40 promoter activation and IL-23 production in the terminal ileum mediated by dendritic cells. J. Clin. Invest. 112:693-706. doi:10.1172/JCI200317464.

22. Hilliard, B.A., et al. 2002. Critical roles of c-Rel in autoimmune inflammation and helper $\mathrm{T}$ cell differentiation. J. Clin. Invest. 110:843-850. doi:10.1172/JCI200215254.

23. Zhang, Z., et al. 2005. Interleukin-1beta and tumor necrosis factor-alpha upregulate interleukin-23 subunit p19 gene expression in human colonic subepithelial myofibroblasts. Int. J. Mol. Med. 15:79-83.

24. Das, J., et al. 2001. A critical role for NF-kappa B in GATA3 expression and TH2 differentiation in allergic airway inflammation. Nat. Immunol. 2:45-50.

25. Schnare, M., et al. 2001. Toll-like receptors control activation of adaptive immune responses. Nat. Immunol. 2:947-950.

26. Pahl, A., Zhang, M., Kuss, H., Szelenyi, I., and Brune, K. 2002. Regulation of IL-13 synthesis in human lymphocytes: implications for asthma therapy. Br. J. Pharmacol. 135:1915-1926.

27. Lawrance, I.C., et al. 2003. A murine model of chronic inflammation-induced intestinal fibrosis down-regulated by antisense NF-kappa B. Gastroenterology. 125:1750-1761.

28. Li, Q., and Verma, I.M. 2002. NF-kappaB regulation in the immune system. Nat. Rev. Immunol. 2:725-734

29. Kotani, H., Nakajima, T., Lai, S., Morishita, R., and Kaneda, Y. 2004. The HVJ-envelope as an innovative vector system for cardiovascular disease. Curr. Gene Ther 4:183-194.

30. Morishita, R., et al. 1997. In vivo transfection of cis element "decoy" against nuclear factor-kappaB binding site prevents myocardial infarction. Nat. Med. 3:894-899.

31. Tomita, N., Ogihara, T., and Morishita, R. 2003. Transcription factors as molecular targets: molecular mechanisms of decoy ODN and their design. Curr. Drug Targets. 4:603-608.

32. Gambari, R. 2004. New trends in the development of transcription factor decoy (TFD) pharmacotherapy. Curr. Drug Targets. 5:419-430.

33. Kaneda, Y., et al. 2002. Hemagglutinating virus of Japan (HVJ) envelope vector as a versatile gene delivery system. Mol. Ther. 6:219-226. 
34. Shimamura, M., et al. 2004. Novel therapeutic strategy to treat brain ischemia: overexpression of hepatocyte growth factor gene reduced ischemic injury without cerebral edema in rat model. Circulation. 109:424-431.

35. Tominaga, N., et al. 2003. Development of Th1 and not Th2 immune responses in mice lacking IFNregulatory factor-4. Int. Immunol. 15:1-10.

36. Hu, C.M., Jang, S.Y., Fanzo, J.C., and Pernis, A.B. 2002. Modulation of T cell cytokine production by interferon regulatory factor-4. J. Biol. Chem. 277:49238-49246.

37. Saeki, Y., et al. 1997. Development and characterization of cationic liposomes conjugated with HVJ (Sendai virus): reciprocal effect of cationic lipid for in vitro and in vivo gene transfer. Hum. Gene Ther. 8:2133-2141.

38. Papa, S., Zazzeroni, F., Pham, C.G., Bubici, C., and Franzoso, G. 2004. Linking JNK signaling to NFkappaB: a key to survival. J. Cell Sci. 117:5197-5208.

39. Tang, G., et al. 2001. Inhibition of JNK activation through NF-kappaB target genes. Nature. 414:313-317.

40. Stehlik, C., de Martin, R., Binder, B.R., and Lipp, J. 1998. Cytokine induced expression of porcine inhibitor of apoptosis protein (iap) family member is regulated by NF-kappa B. Biochem. Biophys. Res. Commun. 243:827-832.

41. Watanabe, T., Kitani, A., Murray, P.J., and Strober, W. 2004. NOD2 is a negative regulator of Toll-like receptor 2 -mediated $\mathrm{T}$ helper type 1 responses. Nat. Immunol. 5:800-808.

42. Lawrence, T., Gilroy, D.W., Colville-Nash, P.R., and Willoughby, D.A. 2001. Possible new role for NFkappaB in the resolution of inflammation. Nat. Med. 7:1291-1297.

43. Tomita, T., et al. 1999. Suppressed severity of collagen-induced arthritis by in vivo transfection of nuclear factor kappaB decoy oligodeoxynucleotides as a gene therapy. Arthritis Rheum. 42:2532-2542.

44. Suzuki, J., Morishita, R., Amano, J., Kaneda, Y., and Isobe, M. 2000. Decoy against nuclear factorkappa B attenuates myocardial cell infiltration and arterial neointimal formation in murine cardiac allografts. Gene Ther. 7:1847-1852.

45. Ogushi, I., et al. 2003. Nuclear factor kappa B decoy oligodeoxynucleotides prevent endotoxin-induced fatal liver failure in a murine model. Hepatology.
38:335-344.

46. Kim, K.W., et al. 2005. Increased interleukin-17 production via a phosphoinositide 3-kinase/Akt and nuclear factor kappaB-dependent pathway in patients with rheumatoid arthritis. Arthritis Res. Ther. 7:R139-R148.

47. Kim, S.W., et al. 2004. Catalposide, a compound isolated from catalpa ovata, attenuates induction of intestinal epithelial proinflammatory gene expression and reduces the severity of trinitrobenzene sulfonic acid-induced colitis in mice. Inflamm. Bowel Dis. 10:564-572.

48. Matsumoto, S., et al. 2004. Fucoidan derived from cladosiphon okamuranus tokida ameliorates murine chronic colitis through the down-regulation of interleukin- 6 production on colonic epithelial cells. Clin. Exp. Immunol. 136:432-439.

49. Sugimoto, K., et al. 2002. Curcumin prevents and ameliorates trinitrobenzene sulfonic acid-induced colitis in mice. Gastroenterology. 123:1912-1922.

50. Hollenbach, E., et al. 2004. Inhibition of p38 MAP kinase- and RICK/NF-kappaB-signaling suppresses inflammatory bowel disease. FASEB J. 18:1550-1552.

51. Segain, J.P., et al. 2003. Rho kinase blockade prevents inflammation via nuclear factor kappa $B$ inhibition: evidence in Crohn's disease and experimental colitis. Gastroenterology. 124:1180-1187.

52. Takagi, T., et al. 2002. Pioglitazone, a PPAR-gamma ligand, provides protection from dextran sulfate sodium-induced colitis in mice in association with inhibition of the NF-kappaB-cytokine cascade. Redox Rep. 7:283-289.

53. Herfarth, H., et al. 2000. Nuclear factor-kappa B activity and intestinal inflammation in dextran sulphate sodium (DSS)-induced colitis in mice is suppressed by gliotoxin. Clin. Exp. Immunol. 120:59-65.

54. Zhou, Y., et al. 2003. Nonsteroidal anti-inflammatory drugs can lower amyloidogenic Abeta42 by inhibiting Rho. Science. 302:1215-1217.

55. Hirooka, Y., Shimokawa, H., and Takeshita, A. 2004. Rho-kinase, a potential therapeutic target for the treatment of hypertension. Drug News Perspect. 17:523-527.

56. Hashimoto, K., et al. 2002. Suppression of airway hyperresponsiveness induced by ovalbumin sensitisation and RSV infection with Y-27632, a Rho kinase inhibitor. Thorax. 57:524-527.

57. Russell, F.D., and Molenaar, P. 2004. Investigation of signaling pathways that mediate the inotropic effect of urotensin-II in human heart. Cardiovasc. Res. 63:673-681.

58. Kweon, Y.O., et al. 2003. Gliotoxin-mediated apoptosis of activated human hepatic stellate cells. J. Hepatol. 39:38-46.

59. Waring, P., Sjaarda, A., and Lin, Q.H. 1995. Gliotoxin inactivates alcohol dehydrogenase by either covalent modification or free radical damage mediated by redox cycling. Biochem. Pharmacol. 49:1195-1201.

60. Vulcano, M., et al. 2001. Dendritic cells as a major source of macrophage-derived chemokine/CCL22 in vitro and in vivo. Eur. J. Immunol. 31:812-822.

61. Nakayama, T., et al. 2004. Selective induction of Th2-attracting chemokines CCL17 and CCL22 in human B cells by latent membrane protein 1 of Epstein-Barr virus. J. Virol. 78:1665-1674.

62. Berin, M.C., Dwinell, M.B., Eckmann, L., and Kagnoff, M.F. 2001. Production of MDC/CCL22 by human intestinal epithelial cells. Am. J. Physiol. Gastrointest. Liver Physiol. 280:G1217-G1226.

63. Elewaut, D., et al. 2003. NIK-dependent RelB activation defines a unique signaling pathway for the development of V alpha 14i NKT cells. J. Exp. Med. 197:1623-1633.

64. Lee, C.G., et al. 2001. Interleukin-13 induces tissue fibrosis by selectively stimulating and activating transforming growth factor beta(1). J. Exp. Med. 194:809-821.

65. Kitani, A., et al. 2003. Transforming growth factor (TGF)-beta1-producing regulatory $\mathrm{T}$ cells induce Smad-mediated interleukin 10 secretion that facilitates coordinated immunoregulatory activity and amelioration of TGF-beta1-mediated fibrosis. J. Exp. Med. 198:1179-1188.

66. Atreya, R., et al. 2000. Blockade of interleukin 6 trans signaling suppresses T-cell resistance against apoptosis in chronic intestinal inflammation: evidence in crohn disease and experimental colitis in vivo. Nat. Med. 6:583-588.

67. Boirivant, M., Strober, W., and Fuss, I.J. 2005. Regulatory cells induced by feeding TNP-haptenated colonic protein cross-protect mice from colitis induced by an unrelated hapten. Inflamm. Bowel Dis. 1:48-55. 